\title{
Continuous monitoring of the 2015-2018 Nevado del Ruiz activity, Colombia, using satellite infrared images and local infrasound records
}

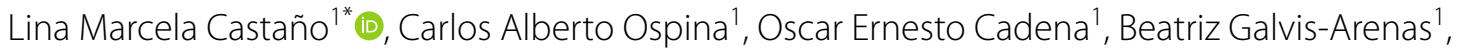 \\ John Makario Londono', Carlos Andrés Laverde', Takayuki Kaneko² and Mie Ichihara²
}

\begin{abstract}
Nevado del Ruiz Volcano (NRV) had a phreatomagmatic eruption in 1985. The eruption partially melted the volcano's ice cap leading to floods and lahars flowing down to nearby towns, which killed at least 25,000 people. This event has raised particular importance of monitoring activity including small eruptions at ice-capped high-altitude volcanoes. However, the high altitude makes it difficult to maintain monitoring stations near the summit crater. Moreover, the visibility of the summit area is frequently prevented by clouds. In this paper, we report the results of a feasibility study for detecting thermal anomalies and small eruptions using satellite thermal remote sensing and ground-based infrasound technique. We newly included South and Central America to the observation areas of the near-real-time monitoring system of the active volcanoes, which uses infrared images from satellites. We also operated three infrasound stations in the distances of 4-6 km from the active crater. Each of the stations consisted of a pair of infrasound sensors, and a cross-correlation technique was applied. The thermal and infrasound data acquisition started in August 2015 and December 2016, respectively, and recorded the recent dome-forming activity of NRV. We proposed parameters representing the visibility of the thermal anomalies and infrasound signals. These parameters are useful for monitoring because the severe weather condition at NRV frequently prevents signal detections. We discussed the detected thermal anomalies and infrasound signals in comparison with their visibilities and the changes in the volcanic activity of NRV reported by the local observatory. The thermal anomaly and infrasound detections were consistent with the high eruptive activity occurring at the NRV from October 2015 to May 2017 and its subsequent decline. Within the active period, there were breaks in the detections of thermal anomaly and infrasound. The visibility analyses allowed us to interpret the breaks as a result of bad weather conditions and to distinguish them from the confirmed low-activity periods after May 2017.
\end{abstract}

Keywords: Infrasound, Cross-correlation, Thermal anomaly, Visibility, Remote sensing, Nevado del Ruiz, Colombia

\section{Introduction}

Monitoring of high-altitude volcanoes in tropical zones is very difficult, which is a serious issue in the mitigation of volcanic disasters in these areas. Thermal and infrasound

\footnotetext{
*Correspondence: Imcastano@sgc.gov.co

1 Servicio Geológico Colombiano, Bogota, Colombia

Full list of author information is available at the end of the article
}

monitoring techniques are widely used tools for tracking and quantifying the surface activity of volcanoes (e.g., Kaneko et al. 2010a, b, 2019; Ripepe et al. 2018; Laiolo et al. 2019).

Thermal anomalies are features that provide information about the surface thermal state of the volcanoes. Anomalous changes in the surface temperature are associated with variations of heat flux from the underground 
to the surface (Oppenheimer 1998). Thermal variations at volcanoes can indicate unrest, eruptive crisis, ongoing eruptive processes, or precursors to more energetic explosive/effusive activity (Dean and Dehn 2015). Thus, the continuous recording of thermal data for different eruptive types, stages, or cycles in the volcano is very useful for distinguishing clearly the cause of the anomaly.

Satellite-based infrared sensors can detect volcanic thermal features. These instruments are useful tools for monitoring volcanoes that are active or potentially active but are poorly instrumented (e.g., Dean et al. 1998; Kaneko et al. 2010a). Because satellite sensors make daily or semi-daily observations of a region with moderate to high resolutions, a number of near-real-time systems based on automated algorithms have been implemented (Harris et al. 2001; Dehn et al. 2002; Wright et al. 2002, 2004; Coppola et al. 2009, 2016). REALVOLC (Kaneko et al. 2002, 2010a) is one of the automated monitoring systems for tracking thermal anomaly using satellite data from Moderate Resolution Imaging Spectroradiometer (MODIS) and Multi-functional Transport Satellite (MTSAT) sensors. This system has been in operation since 2010, monitoring 147 active volcanoes in East Asia, and it has captured the eruptive sequences of Mt. Asama (Japan) and Sarychev Peak (Russia) volcanoes (Kaneko et al. 2006, 2010a, b).

Infrasound signals from large eruptions are detected worldwide and are used for global monitoring of eruptions, including those at remote volcanoes. The pioneer works are Passechnik (1959) at the Bezymyanny volcano (Kamchatka, Russia) and Goerke et al. (1965) at the Agung volcano (Bali, Indonesia). In recent years, highperformance infrasound stations are operated as a part of the International Monitoring System (IMS) for verification of the Comprehensive Nuclear-Test-Ban Treaty (CTBT) and are also used for monitoring and studying volcanic eruptions (Evers and Haak 2005; Le Pichon et al. 2010; Matoza et al. 2017; Marchetti et al. 2019).

Local infrasound observation is necessary for monitoring small eruptions and gas emissions (Johnson et al. 2003; Lopez et al. 2013; Ulivieri et al. 2013), and for quick detection of eruptions (Ripepe et al. 2018). The wind noise problem is particularly severe for the detection of signals from small eruptions at high altitudes. Recording with multiple sensors in an array effectively distinguishes signals from noise (Ripepe and Marchetti 2002; Matoza et al. 2007). Most of the array observations were made temporally, while permanent infrasonic arrays are operated only at a limited number of well-monitored volcanos such as Stromboli and Etna in Italy (Ripepe et al. 2007; Ulivieri et al. 2013) and Kilauea in Hawaii (Thelen and Cooper 2014). An alternative method to distinguish infrasonic signals from wind noise was to make cross-correlation analyses between signals from an infrasound sensor and a collocated seismometer (Ichihara et al. 2012). The method was applied at many volcanoes with some improved analytical techniques (e.g., Cannata et al. 2013; McKee et al. 2018). However, the method does not work when a volcano is seismically very active (Ichihara et al. 2012).

In this study, we apply thermal and infrasonic methods designed for continuous monitoring for the 2015-2018 activity of NRV. A phreatomagmatic eruption of NRV in 1985 caused one of the most significant volcanic disasters in history. The eruption partially melted the volcano's ice cap leading to floods and lahars flowing down to nearby towns, which killed at least 25,000 people. This event has raised the particular importance of monitoring ice-capped high-altitude volcanoes. However, the high altitude makes it difficult to maintain stations near the summit crater. Moreover, the visibility of the summit area is frequently prevented by clouds. The satellite thermal monitoring system is operated since August 2015, and the new infrasonic stations are since December 2016. They recorded data during the recent dome-forming activity and a series of small eruptions. Because the activity was also routinely reported by the local observatory of Colombian Geological Survey (SGC-OVSM) with multiparametric monitoring data, we had a rare opportunity to make a feasibility study of detecting the surface activity by the thermal and infrasonic methods at a high-altitude volcano in a tropical region.

\section{Recent activity of Nevado del Ruiz Volcano (NRV)}

NRV is one of the most active volcanoes in Colombia with a height of $5321 \mathrm{~m}$ above sea level locating in the Cordillera Central de Colombia ( $4^{\circ} 53^{\prime} 43^{\prime \prime} \mathrm{N} ; 75^{\circ} 19^{\prime}$ $\left.21^{\prime \prime} \mathrm{W}\right)$, approximately $140 \mathrm{~km}$ North-West of Bogotá and $28 \mathrm{~km}$ South-East of Manizales city (Fig. 1a). It is an andesitic volcano with recent activity at least in the last $\approx 10$ kyrs mainly explosive in nature (Martínez et al. 2014; Ceballos-Hernández et al. 2019).

NRV became unrest in 1984, and the first eruption took place on September 11, 1985, followed by the deadly event of November 13, 1985. After that, frequent minor eruptions occurred between 1986 and 1989, and a new phreatomagmatic eruption on September 1, 1989. From 1990 to 2002, several minor volcanic crises occurred. Between 2002 and 2006, NRV decreased its activity. A new cycle of activity started in 2007 (Londono 2016), with surface manifestations at the end of 2010. Temporal changes in seismicity, deformation, and geochemistry $\left(\mathrm{SO}_{2}\right.$ release mainly) have been observed since then, with changes in the dynamics of the current eruptive episode (Castaño-López et al. 2017). Two small phreatomagmatic eruptions took place in May and June 2012 (Martínez 


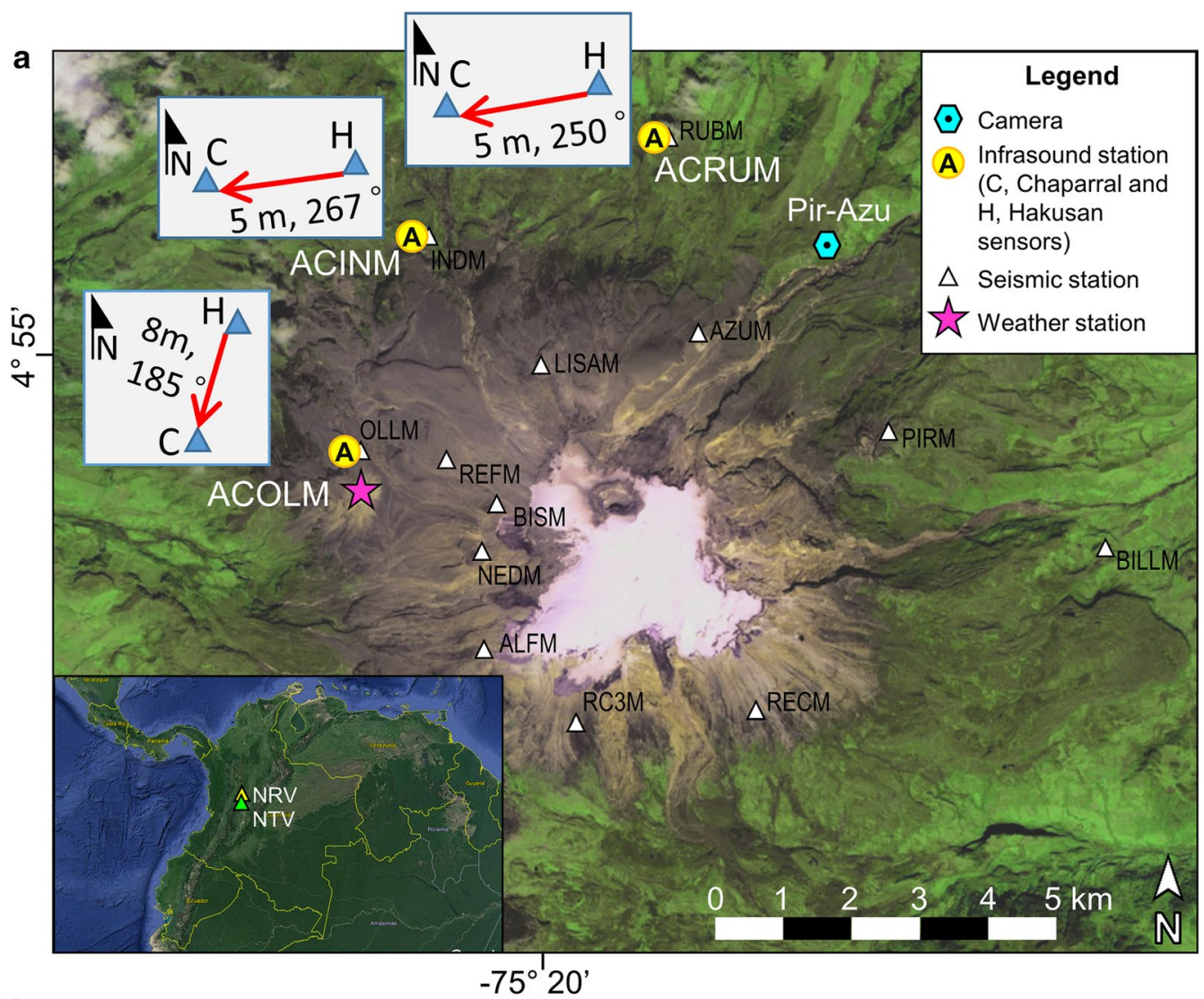

b

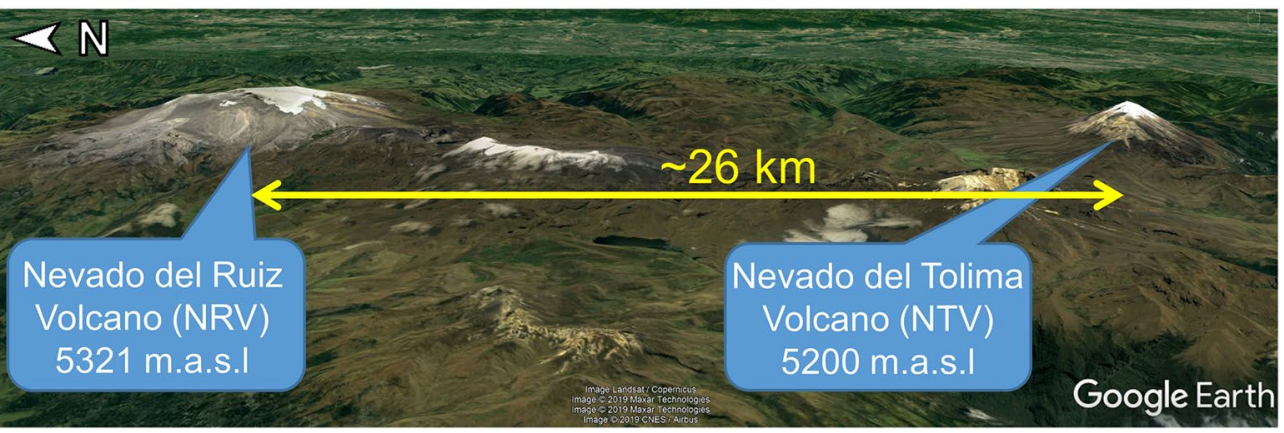

Fig. 1 Map of the location of Nevado del Ruiz volcano (NRV). a Monitoring network at NRV. The square boxes at three infrasound stations show the alignments of two infrasound sensors (a Chaparral 60Vx sensor at ' $\mathrm{C}^{\prime}$ and a Hakusan SI104 sensor at ' $\mathrm{H}$ '). The distances of the stations from the NRV crater are $4.2 \mathrm{~km}$ (ACOLM), $5.3 \mathrm{~km}$ (ACINM), and $6.0 \mathrm{~km}$ (ACRUM). b Location of Nevado del Tolima Volcano (NTV) close to NRV. The image sources are RapidEye Satellite image in 2010 for a, and Google Earth (Landsat/Copernicus with copyrights of Maxar Technologies and CNES/Airbus) for b

et al. 2012). Later on, in October 2015, an effusive eruption occurred, with the emplacement of a small lava dome at the bottom of the active crater. Small Vulcanian eruptions have been recorded frequently during these eruptive periods (Londono and Galvis 2018).

Figure 2 summarizes some of the parameters that SGC used for monitoring the activity of NRV (SGC Servicio Geológico 2015, 2016, 2017, 2018). Londono and Galvis (2018) calculated the volume of ash emission for selected events by $1 \mathrm{D}$ modeling of a volcanic plume using the observed column height from ground photographic images and the eruption duration obtained from the seismic signal synchronized with the images. The evaluated volumes are shown in Fig. 2c with daily counts of ash emission events. The possible volume of the extruded lava dome (Fig. 2e) was calculated from 57 available satellite images from TerraSAR-X (TSX)/TanDEM-X (TDX) radar satellites (see Appendix A). 


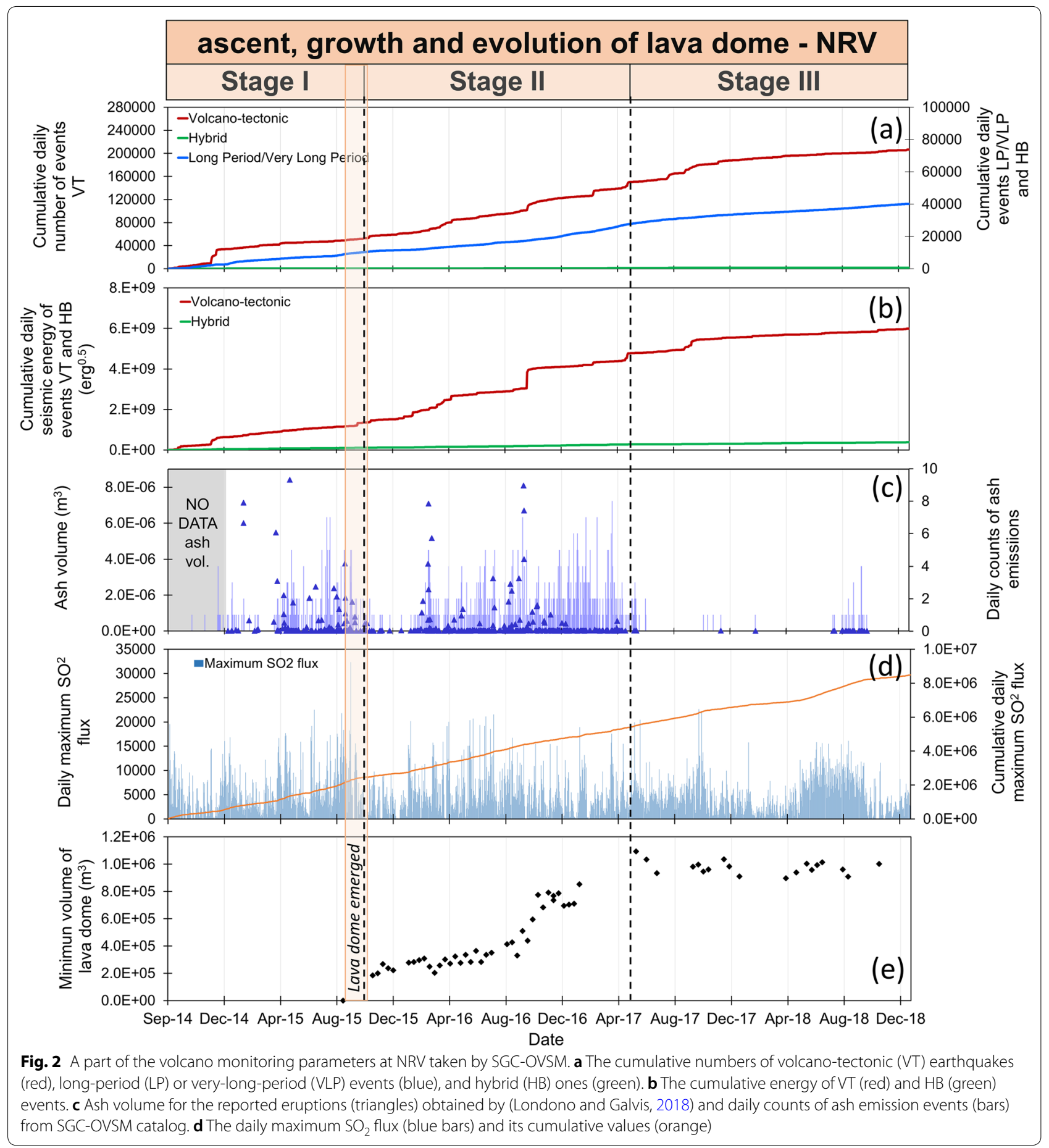

Combining Fig. 2 and reports from the volcano monitoring (e.g., SGC Servicio Geológico 2015, 2016, 2017, 2018), we have defined three stages of the volcanic activity for the period from November 2014 to December 2018. Stage I, from November 2014 to October 2015, corresponds to a period of magma ascent with high seismicity (Fig. 2a, b) and volcanic tremor (continuous and pulsating), edifice deformation, ash emissions (Fig. 2c), and $\mathrm{SO}_{2}$ release (Fig. 2d) (Lundgren et al. 2015; SGC Servicio Geológico 2015; Londono 2016). At the end of Stage I, a lava dome started emplacement at the bottom of the crater (Fig. 2e). Stage II, from October 
2015 to May 2017, corresponds to a dome growth period with a new possible input of magma to the initial volume (Fig. 2e), accompanying the significant increase of ash emissions (Fig. 2c), seismicity (Fig. 2a, b), $\mathrm{SO}_{2}$ (Fig. 2d), and volcanic tremor episodes with moderate deformation (SGC Servicio Geológico 2015, 2016, 2017). Stage III, from May 2017 to December 2018, corresponds to final emplacement and subsequent lava dome evolution, which accompanied minor ash emissions (Fig. 2c), continuous and variable $\mathrm{SO}_{2}$ release (Fig. 2d), low seismicity levels (Fig. 2a, b) and very low deformation. We will compare such division of Stages I-III with the detected thermal anomalies and infrasound data.

\section{Methods, data, and data processing Thermal anomalies}

REALVOLC is a near-real-time monitoring system used in active volcanoes to track the volcanic surface thermal state and evaluate their level of activity. Since August 2015, the REALVOLC system has started covering the Central and South America regions, with more than 80 active volcanoes in the Andes mountain range monitored. In Colombia, 11 out of the 23 active volcanoes have been included in the web-based system (http://vrsse rv2.eri.u-tokyo.ac.jp/index.html).

For NVR and other volcanoes, the system uses level $1 \mathrm{~b}$ nighttime MODIS infrared images. These images are acquired by sensors mounted on the NASA Terra and Aqua satellites with a horizontal spatial resolution of $1 \mathrm{~km}$ per pixel. MODIS data are downloaded from the NASA LAADS web service and each image or scene is trimmed at $101 \times 101$ pixels as a preprocessing area. The analyzed area is $6 \times 6 \mathrm{~km}$ centered on the volcano summit (Fig. 3a). We process and analyze, through an automatic main routine, the calibrated radiances from the nighttime MODIS 21 and 31 bands with the central wavelength at $3.9 \mu \mathrm{m}$ and $11 \mu \mathrm{m}$, respectively (Kaneko et al. 2006, 2010a). Calibrated radiances at the MODIS $3.9 \mu \mathrm{m}$ and $11 \mu \mathrm{m}$ bands were converted to brightness temperatures using the Planck function (Rothery et al. 1988). The band 21 is used for detecting thermal anomalies on volcanoes, while band 31 is for inferring the background temperature of the region (Wooster and Rothery 1997). The obtained data from both bands are plotted together to show the thermal anomaly compared with the background temperature (Fig. 3b).

In the analysis of background temperature level, we used time-series data from Nevado del Tolima volcano (NTV) approximately $26 \mathrm{~km}$ at the South-Southwest of NRV (Fig. 1). This analysis was done to establish a baseline related to the regional climatology, as NTV (height $5220 \mathrm{~m}$ a.s.l) has topographic and glacial characteristics similar to NRV, while it showed low volcanic activity levels during the studied period.

Thermal radiance from the NRV is very low when the target area is covered by clouds. To eliminate these unreliable low-temperature values due to the poor visibility of the ground surface, a statistical data filtering method was applied. For a sliding time window of \pm 10 days centered at each day, we selected the maximum $10 \%$ of Band 31 values and took their mean. This method gave us the baseline of the temperature, excluding the data affected by clouds. The threshold to accept a value as a data point was that both values of Bands 31 and 21 were larger than the baseline value. The fraction of the accepted data points in sliding 4-day windows was used as the visibility of the thermal anomaly of the period, which we refer to ThVis. The length of 4 days was used because the data intervals are approximately 1 day (one or two points during the nighttime every day) and the cloud condition can change in less than a week. It is noted that ThVis thoroughly represents the weather condition and is independent of the volcanic activity.

\section{Infrasound}

Some infrasound stations had been operated at NRV, each of which had a single infrasound sensor collocated with a seismometer. However, we could not resolve infrasound signals covered with wind noise. The crosscorrelation method using an infrasound sensor and a collocated seismometer (Ichihara et al. 2012) was not useful at NRV due to the vigorous seismic activity. Therefore, we have newly installed three infrasound stations (ACOLM, ACINM, and ACRUM stations, Fig. 1a), each of which has a pair of infrasound sensors separated by $5-8 \mathrm{~m}$.

The sensor pair consists of a Chaparral 60Vx (frequency range $0.1-200 \mathrm{~Hz}$, full scale $720 \mathrm{~Pa}$, noise level $2 \mathrm{mPa}$ RMS in $0.5-2 \mathrm{~Hz}$ ) and a Hakusan SI104 (frequency range $0.3-2000 \mathrm{~Hz}$, full scale $2 \mathrm{kPa}$, noise level $\sim 0.1$ peak to peak $\mathrm{Pa}$ ). Although the latter sensor has a larger instrumental noise, it has a sensitivity below 0.1 Pa. A Guralp DM26 digitizer records them at $100 \mathrm{~Hz}$ in miniSEED format. Continuous records were available from December 2016. We mainly used ACOLM station because it is the closest to the active crater $(4.2 \mathrm{~km})$ and had the best signal quality. The analysis of infrasound activity was done from December 2016 to November 2018.

We performed the cross-correlation analysis for the two collocated infrasound sensors (' $\mathrm{C}$ ' and ' $\mathrm{H}$ ' in Fig. 1a) to distinguish infrasound signals from wind noise. The detail of the method is explained in Appendix B. The concept of the method is similar to that of Ichihara et al. (2012), who analyzed the records of an infrasound sensor and a collocated seismometer. A frequency band from 1.5 to $8 \mathrm{~Hz}$ was used to guarantee that the distance between 

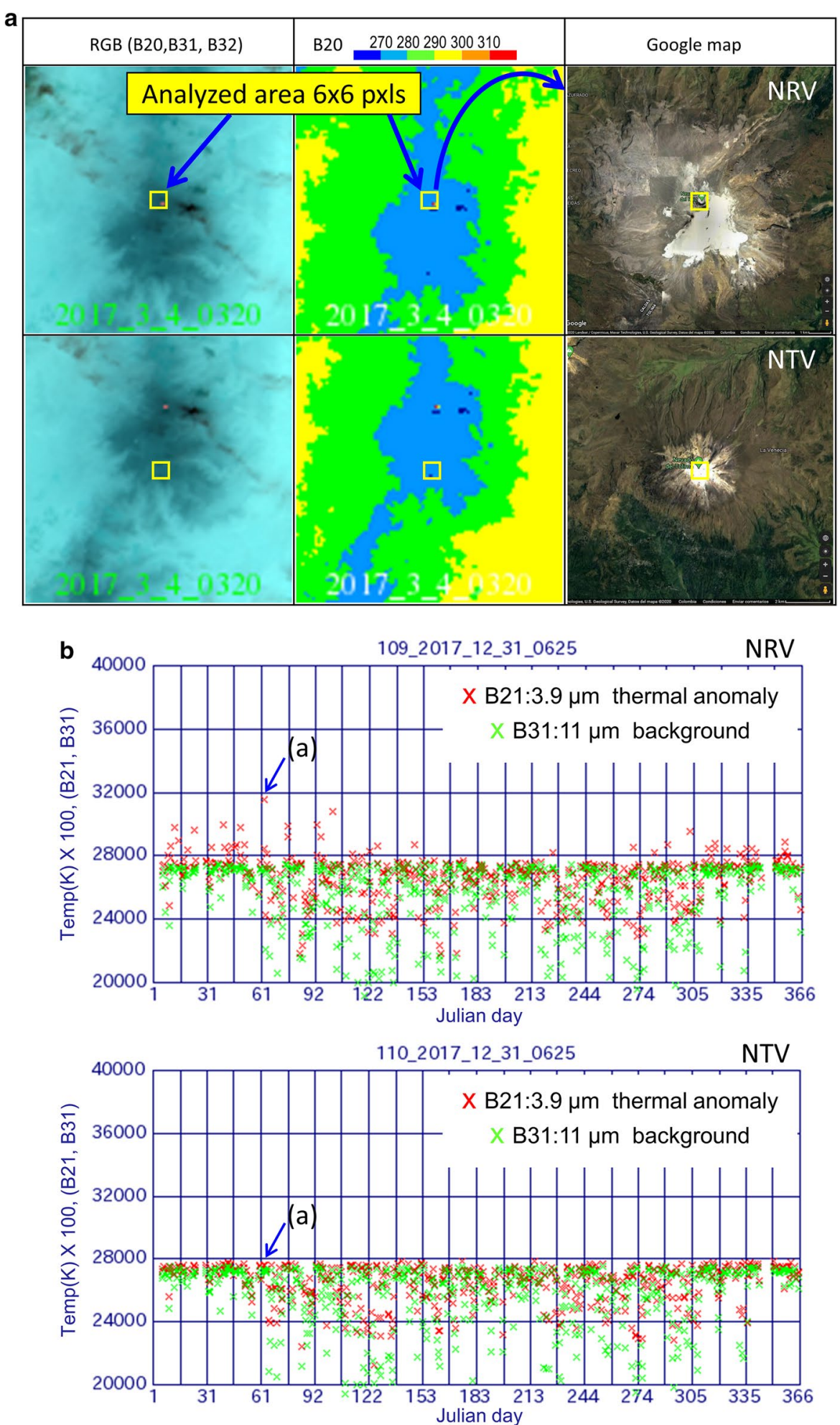

Fig. 3 An example of automatized analyses by REALVOLC. a The target area at NRV for the thermal analyses. $\mathbf{b}$ Thermal radiance as a function of Julian day. The radiance of a pixel in the 3.9- $\mu \mathrm{m}$ band (red crosses) responds to hotspots in the pixel, while that in the 11- $\mu \mathrm{m}$ band (green crosses) represents the mean temperature. We use the 3.9- $\mu \mathrm{m}$ band to detect thermal anomaly and the 11- $\mu \mathrm{m}$ band to estimate the background temperature 


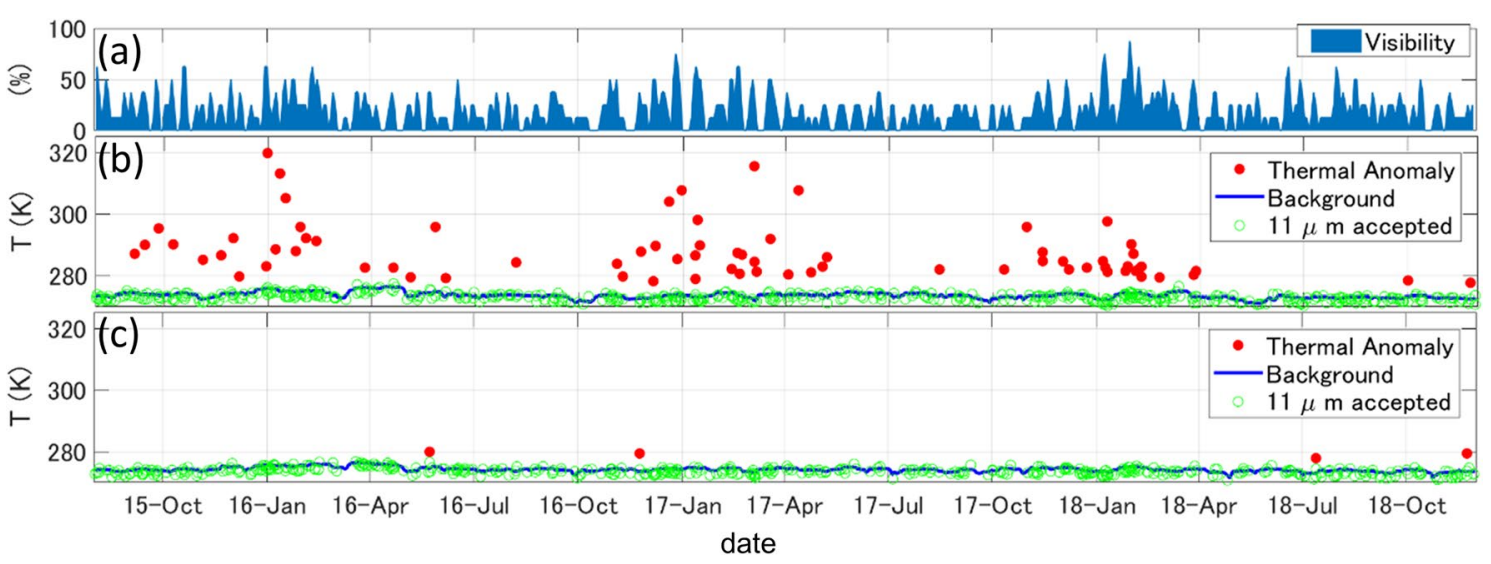

Fig. 4 a The visibility of thermal anomaly (ThVis) at NRV. b, c The accepted data points from the 11- $\mu$ m band (open green circles) and the values from the 3.9- $\mu \mathrm{m}$ band showing significant thermal anomalies (red circles) at NRV (b) and NTV (c). The analysis was made from August 1, 2015, to November 30, 2018. The upper red arrows in $\mathbf{b}$ mark the three periods (P1, P2, P3) of high thermal anomalies at NRV

the sensors was greater than the correlation length of wind noise (Shields, 2005) and much shorter than the wavelengths of infrasound signals. The cross-correlation coefficient of the filtered signals from the sensor pair was calculated using a 5 -s sliding window centered at time $t$, with an overlap of $4 \mathrm{~s}$. It is denoted as $C C\left(X_{C}, X_{H} ; \tau ; t\right)$ in Eq. (B.3), where $X_{C}$ and $X_{H}$ are the filtered data from the sensors ' $\mathrm{C}$ ' and ' $\mathrm{H}$ ', respectively, and $\tau$ is the time lag of $X_{H}$ to $X_{C}$. A daily plot of the cross-correlation coefficient as functions of the $t$ and $\tau$ was analyzed by performing a manual search in every 1-h window to detect cross-correlation patterns associated with infrasound (See Additional file 1).

We considered the average over $20 \mathrm{~s}$ of $t$. A theoretical time lag $\tau$ of an infrasound arrival to the sensor pairs from the crater is approximately zero because the two sensors are close and aligned perpendicular to the direction of the crater. However, the direction of wave propagation can fluctuate due to the wind. Therefore, we take the maximum in $-0.02<\tau<0.02$. The resultant value of $C C$ is represented as $\operatorname{CC}\left(X_{C}, X_{H} ; 0 ; t\right)$.

Like the thermal and visual observations are prevented by clouds, the infrasound signal detection is influenced by wind noise. We define the 'visibility' of infrasound signals as InfVis. To evaluate InfVis, we calculated the mean-square values, $\operatorname{MS}\left(X_{n} ; t\right)$, of the data from each sensor ( $n$ is either $C$ or $H$ ) in the same frequency band $(1.5-8 \mathrm{~Hz})$ and time windows $(20 \mathrm{~s})$ centered at $t$. It includes powers of infrasound signal $\left(A_{n}\right)$, wind noise $\left(W_{n}\right)$, and instrumental noise $\left(N_{n}\right)$, where the subscript indicates the sensor ' $\mathrm{C}$ ' or ' $\mathrm{H}$ '. If MS becomes large due to an increase of power of $A_{n}$, $\mathrm{CC}$ also increases. When only MS increases with CC remaining small, on the contrary, $W_{n}$ or $N_{n}$ is so large that $A_{n}$ is obscured if any. See Appendix B for a further explanation. We compared the maximum value of $\mathrm{CC}\left(X_{C}, X_{H} ; 0 ; t\right)$ (MaxCrr) and the median value $\operatorname{MS}\left(X_{C} ; t\right)$ (MedMS) in every 200-s time window. The time lengths of $20 \mathrm{~s}$ and $200 \mathrm{~s}$ were chosen, referring to the typical lengths of observed infrasound signals at eruptions. As MedMS mainly represents the noise level, the daily fraction of time windows in which MedMS is smaller than a threshold is defined as InfVis. The threshold value is determined by the following analysis.

Detectability analyses for infrasound signals were performed for all three stations by comparing the infrasound correlation patterns with the eruption event catalog. We made the catalog combining the monitoring data (SGC Servicio Geológico 2016, 2017, 2018), including seismic and photographic records as well as eyewitness reports (See Additional file 2: Table S2.1). It includes 311 confirmed eruptions, of which ash plumes are visually observed in 294 cases. The result of infrasound detection was also listed in the catalog (See Additional file 2: Tables S2.1 and S2.2). When we recognized the infrasound signal in the filtered wave trace as well as in the correlation pattern, we list the peak pressure value. The infrasound signal detection or no-detection was then compared with MedMS that represented the noise level.

\section{Results}

\section{Thermal anomalies}

Figure $4 a-c$ shows the results of the analyses for the thermal anomaly and its visibility (ThVis explained in the "Method" section) in the studied period (August 2015November 2018). We applied the same method to the data of the reference volcano, NTV, and confirmed that 
the value in the Band 21 was rarely larger by 5 degrees than the baseline (Fig. 4c). Therefore, we regarded as a thermal anomaly when Band 21 showed a temperature larger by 5 degrees than the baseline. Out of the 8452 time windows at NRV, we accepted 1949 time windows $(23 \%)$ as data points (the Band 21 values are larger than the baseline), 59 of which showed significant thermal anomaly.

NRV showed three periods of thermal anomalies with brightness temperature values ranging between $279 \mathrm{~K}$ and $320 \mathrm{~K}$ (Fig. 4b). Period 1 (P1) from September 2015 to June 2016 had the highest temperature (319.7 K) detected on December 31, 2015. In Period 2 (P2) from October 2016 to May 2017, we observed the maximum value of $315.5 \mathrm{~K}$ on March 4, 2017. The maximum value in Period 3 (P3) from September 2017 to March 2018 was $297.5 \mathrm{~K}$ on January 9. These periods of thermal anomalies were not observed at NTV (Fig. 4c).

The breaks between P1 and P2 and between P2 and P3 seem to correlate with the low thermal visibility (ThVis) at NRV (Fig. 4a). Therefore, it is not obvious whether the thermal activity was low in these breaks only from thermal data. We discuss this point later in "Discussion" section comparing the results with other monitoring parameters.

\section{Infrasound}

Figure 5 shows two example events with infrasound signals recorded at ACOLM during the studied period. Although the signals are covered by wind noise in the raw data traces and are neither distinct in the filtered waveforms, the cross-correlation analyses between the collocated infrasound sensor pairs help to distinguish the infrasound from wind noise. Clear infrasound correlation patterns like those in Fig. 5 were observed in two periods (Table S2.1 in Additional File 2). The first was from December 2016 to May 2017, with acoustic signals associated with ash emissions lasting from 30 to $400 \mathrm{~s}$, with peak pressures ranging from 0.06 to $2.5 \mathrm{~Pa}$ in the filtered waveforms. The second was from July to October 2018, with a maximum pressure value of $2.2 \mathrm{~Pa}$.

Figure 6 presents the result of the statistical analysis of infrasound detection at the three stations. The left column $(a-c)$ compares the maximum values of the cross-correlation coefficient between the sensor pairs in $200 \mathrm{~s}$ (MaxCrr) and the median of the mean-square of the band-passed data in the same window (MedMS). The color dots show the values for the Chaparral sensor (coral) and the Hakusan sensor (medium purple), respectively, in all the time windows from December 2016 to November 2018. The minimum MedMS values of the Chaparral sensor are smaller than those of the Hakusan one because the former has a lower noise level. The values of the Chaparral sensor in time windows corresponding to the events listed in the eruption catalog (See Additional file 2: Table S2.1) are marked, distinguishing the cases that the infrasound signals are noticeable as the cross-correlation pattern (detected) with magenta triangles and not (failed) with black crosses. The green triangles indicate the cases that have clear infrasonic cross-correlation patterns with the volcano's seismic activity but without the confirmed eruptions by cameras or external reports. (See Additional file 2: Table S2.2.) When MaxCrr is large that is the infrasound signal is dominant in the data, most of MedMS values are smaller than $10^{-2} \mathrm{~Pa}^{2}$. It indicates that the average power of the infrasound signal in the time window is smaller than $10^{-2}$ $\mathrm{Pa}^{2}$. When MedMS $>10^{-2} \mathrm{~Pa}^{2}$, it is rare to have MaxCrr larger than 0.4 because wind noise dominates the infrasound signal in the time window. At ACINM (Fig. 6b) and ACRUM (Fig. 6c), the eruption signals are marked as 'detected' even with small values of MaxCrr. These signals were not clear but have been recognized helped by the detection at ACOLM.

The right column of Fig. $6 \mathrm{~d}-\mathrm{f}$ shows the numbers of the eruption events with infrasound detection (magenta) and failure (black) versus the MedMS in the time windows corresponding to the eruption events in the catalog. For the failure cases, we counted only the events that accompanied ash plumes higher than $200 \mathrm{~m}$. sThe detection is very poor when the MedMS is higher than $10^{-2} \mathrm{~Pa}^{2}$ at all the stations. The detections are much less at ACINM and ACRUM than at ACOLM even when MedMS is small enough. We consider the reasons are (1) ACOLM is located closer to the crater than ACINM and ACRUM and (2) it is in the main downwind direction.

We evaluate the infrasound visibility (InfVis) by the daily fraction of the 200-s time windows that had MedMS $<10^{-2} \mathrm{~Pa}^{2}$ at each station (Fig. 7b-d), similarly to the thermal visibility (ThVis) in Fig. 3. We also had wind data at the weather station close to ACOLM (Fig. 1a). We used the average wind speed data recorded with intervals about $10 \mathrm{~min}$ and calculated the daily fraction of the data smaller threshold values of 2,4 , and $8 \mathrm{~m} / \mathrm{s}$ (Fig. 7a). The threshold value of $4 \mathrm{~m} / \mathrm{s}$ gives a similar pattern to InfVis at ACOLM (Fig. 7b), confirming that InfVIs represents the wind noise condition. From December 2016 to May 2017, the InfVis was relatively high, and many signals are detected with eruption events. In both years of 2017 and 2018, the InfVis was low from June to September. In these periods, thermal visibility was also low (Fig. 4). We infer that few events were recognized because the seasonal weather condition caused poor visibility. On the other hand, from October 2017 to June 2018 and from October 2018 to November 2018 (marked by the blue arrows in Fig. 7), the InfVis was high at all the stations. 

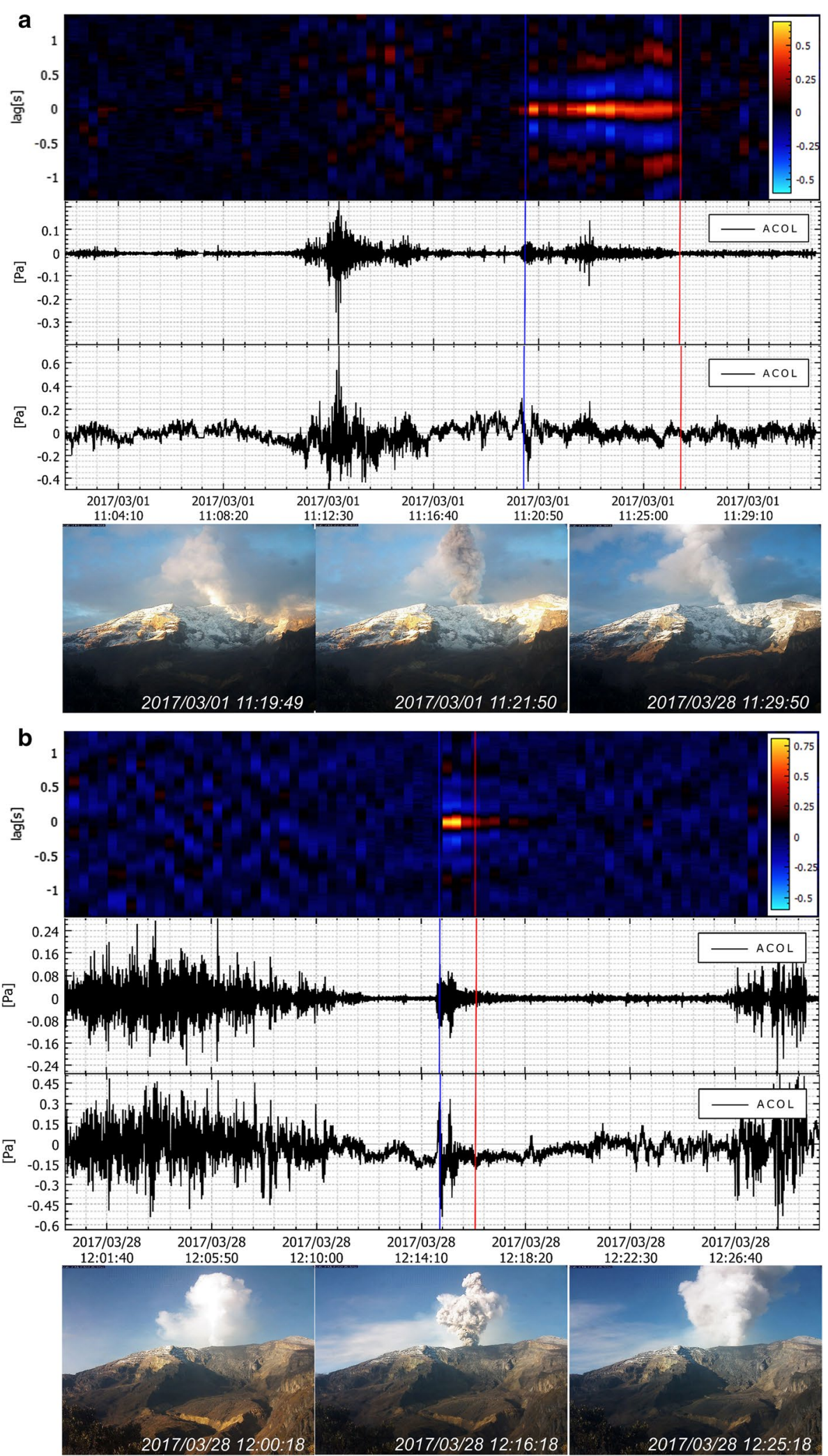

Fig. 5 Examples of infrasound signals (the cross-correlation pattern and filtered/unfiltered wave traces from the Chaparral sensor) at ACOLM station compared with photo images at PIRAÑA-AZUFRADO (Pir-Azu in Fig. 1a) camera. Ash emission events on March 1, 2017, at 11:20 (UTC) (a), and on March 28, 2017, at 12:15 (UTC) (b) 

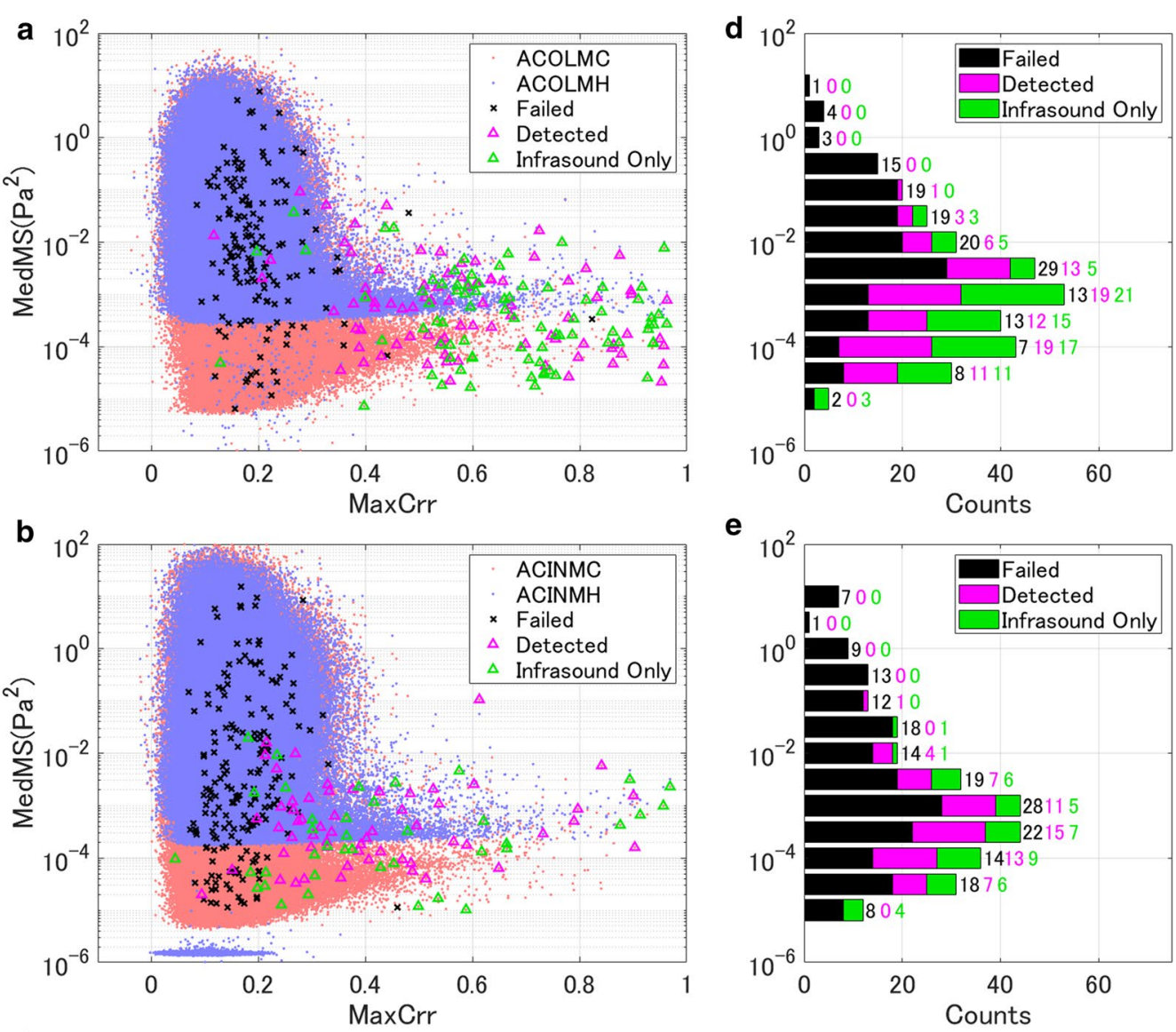

e
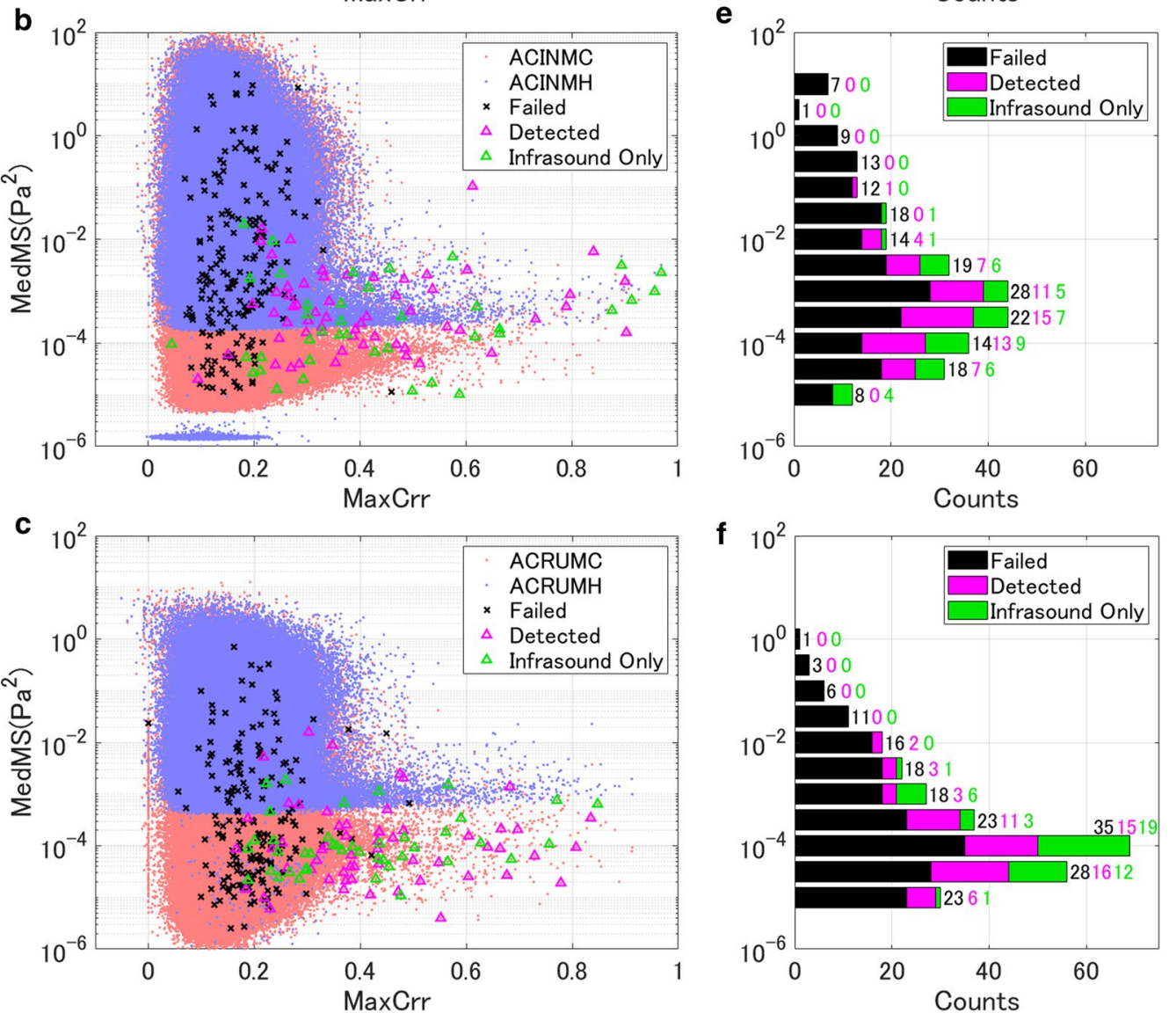

Fig. 6 a-c The maximum cross-correlation coefficient (MaxCrr) and the median of the mean square (MedMS) in 200-s long time windows. Coral and medium purple dots correspond to the data from the Chaparral sensor $(\mathrm{C})$ and the Hakusan sensor $(\mathrm{H})$, respectively. On the values of the Chaparral sensors in the time windows corresponding to the reported eruption event times, whether infrasound detection is failed or successful by the black crosses (failed) and the magenta triangles (detected), respectively. The green triangles indicate the eruptions which have not been confirmed by cameras or reports. $\mathbf{d}$-f Histograms of the events for MedMS. The reported events without and with infrasound detection and the infrasound signals without eruption reports are distinguished by black, magenta, and green colors. The individual counts are shown with the colored numbers besides the bars. The failed case counts only the events with the ash plume heights larger than $200 \mathrm{~m}$. Results are shown for $\operatorname{ACOLM}(\mathbf{a}, \mathbf{d}), \operatorname{ACINM}(\mathbf{b}, \mathbf{e})$, and $\operatorname{ACRUM}(\mathbf{c}, \mathbf{f})$ 


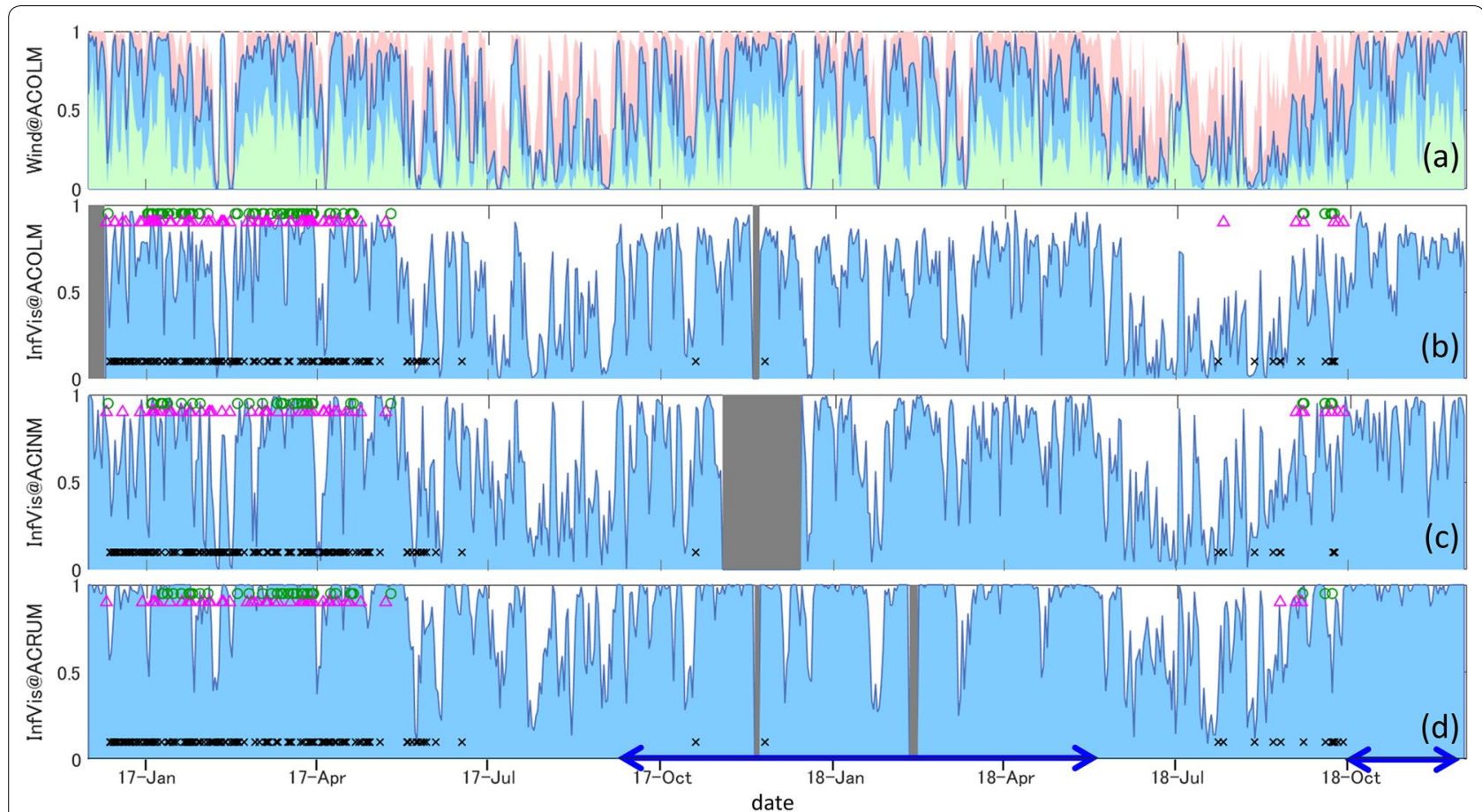

Fig. 7 The visibility of infrasound signals (InfVis) at NRV evaluated by the wind data at the OLLETA weather station close to ACOLM (a) and by the infrasound data at ACOLM (b), ACINM (c), and ACRUM (d). a The daily fraction of wind speed data smaller than the threshold values of $2 \mathrm{~m} / \mathrm{s}$ (green), $4 \mathrm{~m} / \mathrm{s}$ (blue), and $8 \mathrm{~m} / \mathrm{s}$ (pink). b-d The InfVis is shown by blue, and the periods of missing data are shaded. The events to which the associated infrasound signals are detected and failed at the individual station are indicated with the magenta triangles and the black crosses, respectively (see Additional file 2: Table S2.1). The green circles are the unconfirmed events (see Additional file 2: Table S2.2). The blue arrows at the bottom show the periods of low infrasound activity, confirmed by the high InfVis

Nevertheless, infrasound signals detections were rare, confirming that eruption events generating infrasound signals were few. A blue arrow in the bottom of Fig. 7 marks this period.

\section{Discussion}

\section{Comparison with the other monitoring parameters}

The detected thermal anomalies and infrasound are compared with other parameters of the volcanic activity of NRV (Figs. 2 and 8a, b) with consideration of the seasonal change in their visibility.

The thermal analyses started at the end of Stage I when the lava dome emplacement began while the infrasound analyses started at the end Stage II during the lava dome growth (Fig. 2e).

The most significant thermal anomalies (P1 and P2) and infrasound signals are observed in Stage II. The maximum temperature during the studied period was recorded in $\mathrm{P} 1$ and the maximum peak pressure concurs with the beginning of P2. The high temperature may be associated with the extrusion of the lava dome. Such high increases in temperature have been observed at different volcanoes during lava dome extrusions (Wooster and Rothery 1997; Smith et al. 2011; Reaht et al. 2016). From the end of August 2016, the growth rate of the lava dome increased (Fig. 2e). It may have generated the second peak of the thermal anomalies (P2) and high level of infrasound activity.

From May 2017, the growth rate of the lava dome decreased, and the volume stabilized around $1 \times 10^{6}$ $\mathrm{m}^{3}$ during Stage III (Fig. 2e). The P3 period of thermal anomalies was still observed in the first part of Stage III, but the temperature was lower than in P1 and P2. The P3 coincides with the confirmed low level of infrasound activity (the blue arrows in Figs. $7 \mathrm{~d}$ and $8 \mathrm{a}$ ). There were some registered eruptive events in this period but the number of clear ash emission events was only two (November 24 in 2017 and February 6 in 2018 as in Additional file 2: Table S2.1). We infer that when lava dome growth was stopping (Fig. 2e), the volcanic system remained open to allow gas or gas-andash releasing to the atmosphere without significant infrasound signals, and hot enough to produce thermal anomalies.

It is still uncertain whether the breaks in the thermal anomalies between P1, P2, and P3 were real or not. The visibility of infrasound was also low in the breaks due 


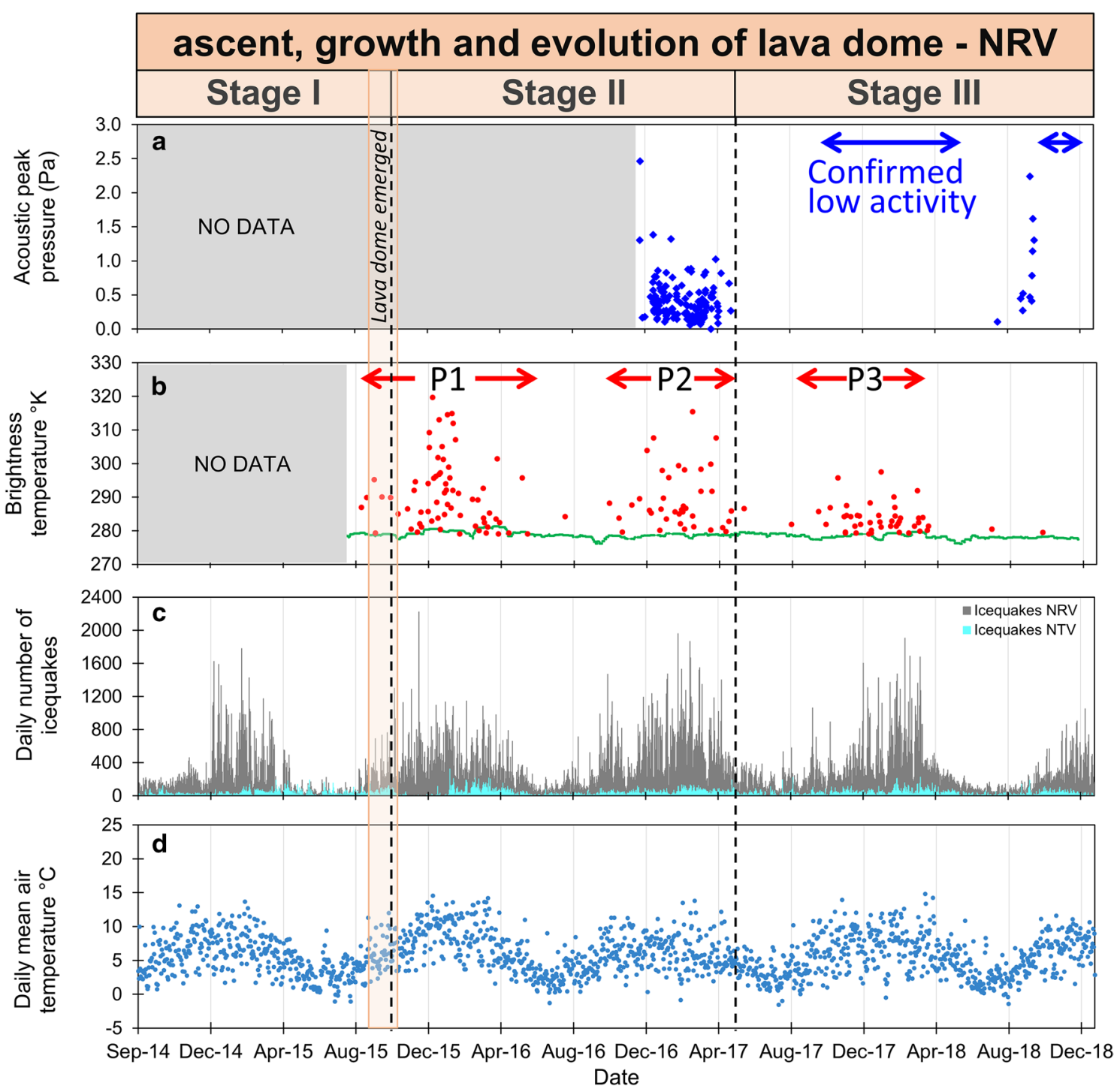

Fig. 8 Comparison of infrasound and thermal data with surface-activity parameters recorded between September 1, 2014, and December 31, 2018. a Maximum pick pressure from the Chaparral sensor data at ACOLM station since December 2016. The periods shown by the blue arrows are the same as those in Fig. 7. b The same thermal anomaly data as in Fig. 4b. c Daily counts of icequakes at NRV (gray) and NTV (light blue). d Air temperature recorded by OLLETA weather station

to strong wind (Fig. 7). Therefore, the breaks may be due to the poor visibility (Fig. 4a).

During the second part of Stage III, no remarkable thermal anomalies were detected even with the sufficiently high visibility values (Fig. 4). A temporal increase in infrasound emissions was observed (Fig. 8a) at the end of Stage III (July to September). The lava dome volume did not increase but varied (Fig. 2e). Such variations may be associated with a new magma batch that ascended to shallower regions, so the intrusion did not affect considerably the temperature of the previous magma batch that formed the first lava dome. The permeability of the conduits may have changed with this new magma input (Pallister et al. 2013; Gaunt et al. 2016), sealing microfractures that partially pressurized the conduits, and allowing the generation of small explosions that exhibited infrasound signals.

\section{Correlation between the thermal anomalies and icequakes}

Figure $8 \mathrm{c}, \mathrm{d}$ shows the number of icequakes (glacier earthquakes) recorded in the seismic stations BISM, RECM and ALFM (Fig. 1a) and air temperature time series of the OLLETA weather station (Fig. 1a). Icequakes are coseismic brittle fracture events within the 
ice generated in glacier-covered areas (Ekström et al. 2003; Podolskiy and Walter 2016), which sometimes produce surface break-off events with infrasound signals (e.g., Preiswerk et al. 2016). There are multiple proposed mechanisms that cause icequakes especially on volcanoes covered by icecap, which include ice falling, ice surface cracking, resonant water-filled ice cavities, sudden changes in water flow rate (St. Lawrence and Qamar 1979; Métaxian 2003), stick-slip sliding (Allstadt and Malone 2014), and crevasse (Neave and Savage 1970). On the other hand, icequakes on volcanoes can be triggered by volcanic activity (Delgado et al. 2015) and/ or thermal stress (Lombardi et al. 2019). The icequakes induced by thermal stress happen when the air temperature decreases during clear nights (no clouds). The number of icequakes increases (Carmichael et al. 2012; Podolskiy et al. 2018; Zhang et al. 2019) possibly due to thermal contraction (caused by significant temperature fluctuation), which induces ice fractures (Lombardi et al. 2019). In Fig. 8b-d, it is possible to observe the increase in daily averaged air temperature and icequakes in synchronicity with thermal anomalies for P1, P2, and P3. Because the visibility of thermal anomalies (ThVis in Fig. 4) is better in clear nights, seasonal atmospheric variations may influence the occurrence of icequakes as well as the ThVis. Nevertheless, we cannot exclude the possibility that the recent surficial activity of NRV affects both of the thermal anomalies and icequakes occurrences. We can see that the number of icequakes suddenly increased in December 2014, and the peak of the icequake numbers in 2018 when the volcanic activity has declined is smaller than the previous 4 years. Also, the number of icequakes in these years at NRV is significantly larger than that at the less active neighbor volcano, NTV (light-blue color in Fig. 8c). A detailed work about this topic is needed to clarify the possible link between icequake and volcanic activity.

\section{Infrasound monitoring for small eruptions at a high-altitude volcano}

In this study, we installed a pair of infrasound sensors separated by less than $10 \mathrm{~m}$ at each station. The crosscorrelation analyses of the data from the sensor pair were useful for detecting weak infrasound signals, which a single sensor could not have resolved. On the other hand, while 101 confirmed eruptions were recorded by either of the infrasound stations, 32 events were detected simultaneously at all the stations (see Additional file 2: Table S2.1). The ACOLM station detected more events than the others, of which reason we consider that ACOLM was the closest to the active vent and located in the main downwind direction as mentioned in the previous section. Although the atmospheric propagation effect is considered significant at larger distances, Lacanna et al. (2014) show that propagating infrasonic power is directional as a result of combined effect of wind and topography even within kilometers. There were also cases that some stations missed the signals due to locally higher noise levels.

The detection would be better if a larger number of infrasound sensors are installed in an array at a station. However, when we have a limited number of sensors, we consider it challenging to concentrate all the sensors at a single station. We propose that the current method, which consists of sensor pairs at multiple stations, is useful for monitoring a high-altitude volcano. The sensor distance is small enough to connect them to a single recorder and a power source so that the costs for installation and maintenance are saved. On the other hand, the current system fails to resolve the infrasound source directions. The main disadvantage is that the sensor pairs are aligned perpendicular to the direction of the active vent. It is better to install them in the line of the vent direction. Even if the sensor separation is as small as $10 \mathrm{~m}$, an infrasound wave propagating from the vent has a time delay larger than $0.02 \mathrm{~s}$, which we could distinguish by the $100-\mathrm{Hz}$ recording.

\section{Concluding remarks}

We made a feasibility study of detecting small eruptions and thermal anomalies of NRV. We analyzed thermal data from satellite remote sensors and infrasound data from newly installed three stations for 2 years and compared the results with the volcano monitoring data by the local observatory (SGC-OVSM). Detection of infrasound signals from small eruptions has been significantly improved by installing a pair of infrasound sensors separated by $5-8 \mathrm{~m}$. Of the three infrasound stations, the closest one located $4.2 \mathrm{~km}$ from the crater to the east made significantly better detection than the others.

Spite of thermal anomalies and infrasound signals were not always detectable over all the studied period, due mainly to weather conditions, we could detect a good number of them and quantify their visibility. Based on the combined analysis using the satellite infrared and infrasound observations, we infer that the activity, which started in November 2014, entered into the main active phases between October 2015 and May 2017, and lowered later on. Within the active period, there were gaps in the detections of thermal anomaly and infrasound. The visibility analyses allowed us to interpret the breaks as atmospheric effects and to distinguish them from the confirmed low-activity periods after May 2017.

Satellite observation of thermal anomalies and infrasound technique is required for monitoring the surface 
activity of high-altitude volcanoes in tropical zones, which frequently have clouds and strong wind. The visibility analyses are essential for interpreting the data. The methods and results shown in this study will be useful for future works in this field.

\section{Supplementary information}

Supplementary information accompanies this paper at https://doi. org/10.1186/s40623-020-01197-z.

\begin{abstract}
Abbreviations
CTBT: Comprehensive Nuclear-Test-Ban Treaty; HB: Hybrid earthquake; IMS: International Monitoring System; LAADS: Level 1 and Atmosphere Archive and Distribution System; LP: Long period earthquake; a.s.l: Above sea level; MaxCrr: Maximum value of the cross-correlation coefficient; MedMS: Median value of the mean square; MODIS: Moderate Resolution Imaging Spectroradiometer; MTSAT: Multi-functional Transport Satellite; NRV: Nevado del Ruiz Volcano; NTV: Nevado del Tolima Volcano; REALVOLC: Near-real time monitoring system of the active volcanoes; SGC: Colombian Geological Survey; TanDEM-X: TanDEM-X radar satellite; TSX: TerraSar-X radar satellite; VT: Volcano-tectonic earthquake.
\end{abstract}

\begin{abstract}
Acknowledgements
We thank the colleagues of Colombian Geological Survey-Volcanological and Seismological Observatory of Manizales (SGC-OVSM) for their support and help in acquisition, storage, management and processing of the multiparameter monitoring data and management of the remote stations. We thank geochemistry and seismology teams (SGC-OVSM) for providing us with data. We also thank H. Kumagai at Nagoya University for leading the SATREPS project. We are also would like grateful for the constructive reviews of the Editor Haruhisa Nakamichi, Dr. Emanuele Marchetti and an anonymous reviewer that significantly improved this manuscript.
\end{abstract}

\begin{abstract}
Authors' contributions
LMC and TK led the thermal anomalies data analysis. CAL participated in the thermal anomalies data analysis and made the lava dome volume analysis. $\mathrm{CAO}, \mathrm{OEC}$, and $\mathrm{MI}$ conducted the infrasound data analysis. BG-A and JML supported the installation of infrasound sensors and participated in infrasound data analysis. LMC and MI led manuscript editing and revisions, and all authors contributed to the scientific discussions. All authors read and approved the final manuscript.
\end{abstract}

\section{Funding}

This work was funded by the SATREPS project "Project for Application of State of the Art Technologies to Strengthen Research and Response to Seismic, Volcanic and Tsunami Events, and Enhance Risk Management in the republic of Colombia (2014-2019, PI: H. Kumagai)" and by the Joint Usage Program of the Earthquake Research Institute, University of Tokyo (2016B03).

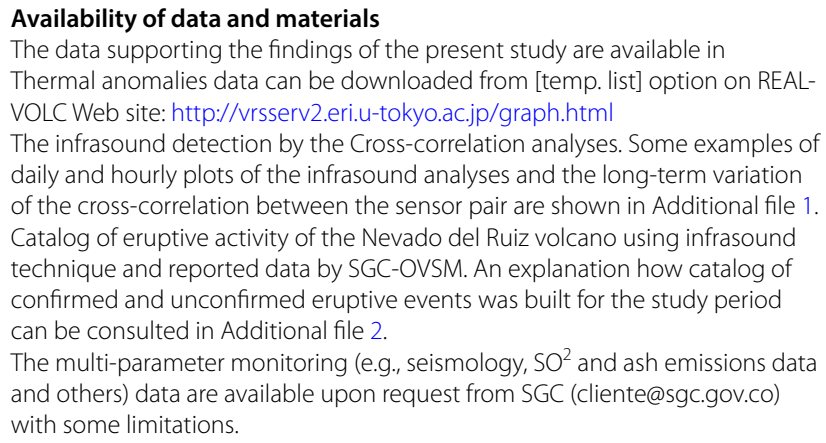

Ethics approval and consent to participate

Not applicable.
Consent for publication

Not applicable.

Competing interests

The authors declare that they have no competing interests.

Author details

${ }^{1}$ Servicio Geológico Colombiano, Bogota, Colombia. ${ }^{2}$ Earthquake Research Institute, The University of Tokyo, Tokyo, Japan.

Additional file 1. The infrasound detection by the cross-correlation analyses.

Additional file 2. Catalog of eruptive activity of the nevado del ruiz volcano using infrasound technique and reported data by SGC-OVSM.

\section{Appendices \\ Appendix A. Estimation of lava dome minimum volume at the NRV}

To quantify the lava dome growing at the bottom of the NRV crater, TerraSAR-X (TSX) and TanDEM-X (TDX) imagery were used. Since only radar amplitude signal imagery ungeoreferenced and unortorectified were available (from https://terrasar-x-archive.terrasar.com/), GIS post-processing was necessary. 31 images from TanDEM$\mathrm{X}$ and 26 images from TerraSAR-X, between November $1^{\mathrm{h}}, 2015$ and October 24, 2018, were processed. All of the images had the same basic characteristics allowing a homogenous accuracy: SpotLight mode (up to 2-m horizontal resolution, scene size $10 \mathrm{~km} \times 10 \mathrm{~km}$ ), night time (around 23:00 UT), ascending path direction and 47 degrees incidence angle. Figure 9 shows an example of this kind of images including the main metadata. Figure 10 shows the main steps of processing. To calibrate the dimensions measurement from the radar images, a georeferenced and ortorectified PlanetScope image of the NRV (showing with clear sky the lava dome) of March 14, 2018 was used. The dimensions of the lava dome in this image was assumed equivalent to the time closest TSX/TDX image of April 9, 2018. Using this calibration, a pixel per meter factor was established (16.9 pixel/m) and applied to all the images. Lava dome area and perimeter were calculated digitizing over each image a polygon bordering the dome. A semi-empirical factor of 2 between dome height and its maximum width was established in order to estimate a minimum approximated volume. A maximal area and volume values of $1.69 \times 10^{4}$ $\mathrm{m}^{2}$ and $1.09 \times 10^{6} \mathrm{~m}^{3}$, respectively were reached at the end of May 2017. Since this date, the extrusive process was almost stopped and lava dome size was stabilized. Variations of $10 \%$ between adjacent measurements are explained because the variable ash deposition and the error margin of the volume estimation method. 


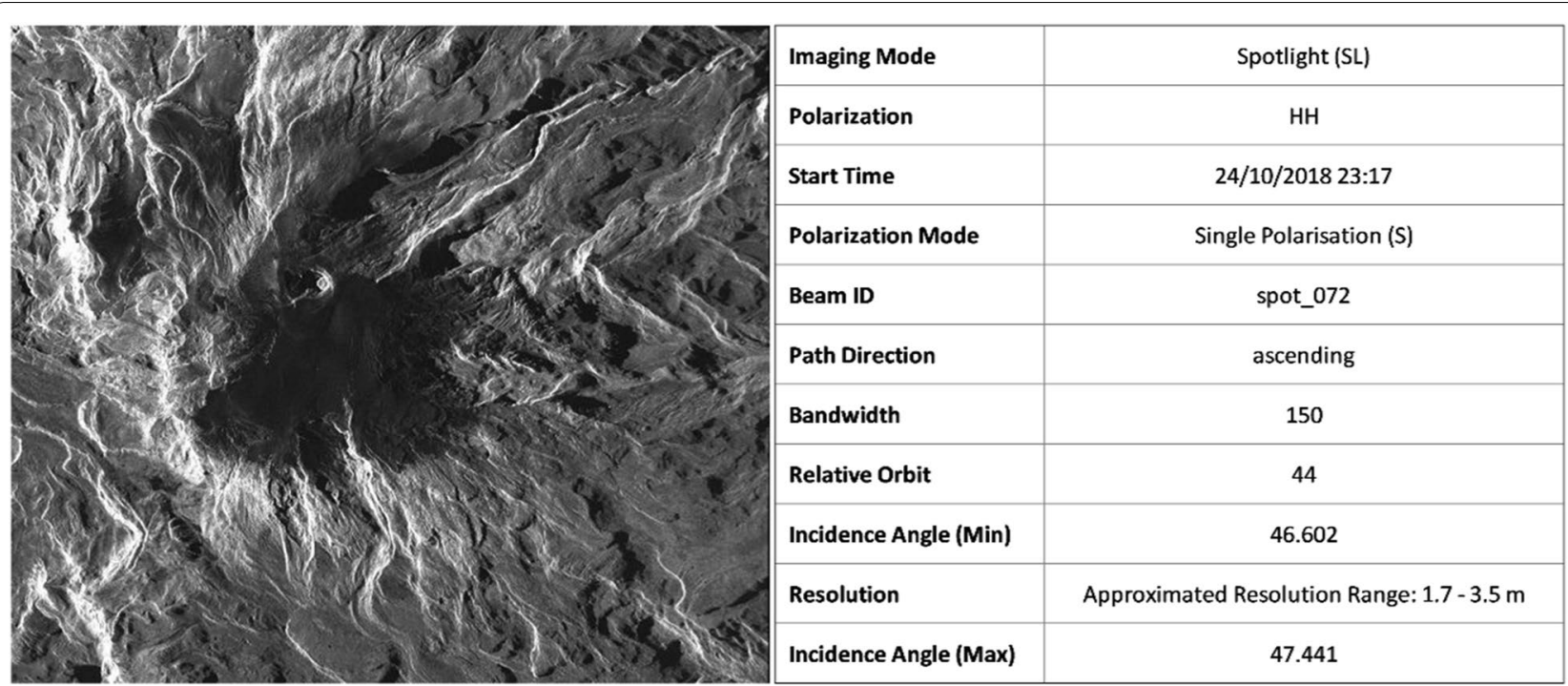

Fig. 9 Image from the NRV zone captured by satellite radar TanDEM-X, October 24, 2018, at 23:17 (UTC). Image metadata at right side. The light blue polygon over the image represented the perimeter of the lava dome extruded at the bottom of the Arenas crater
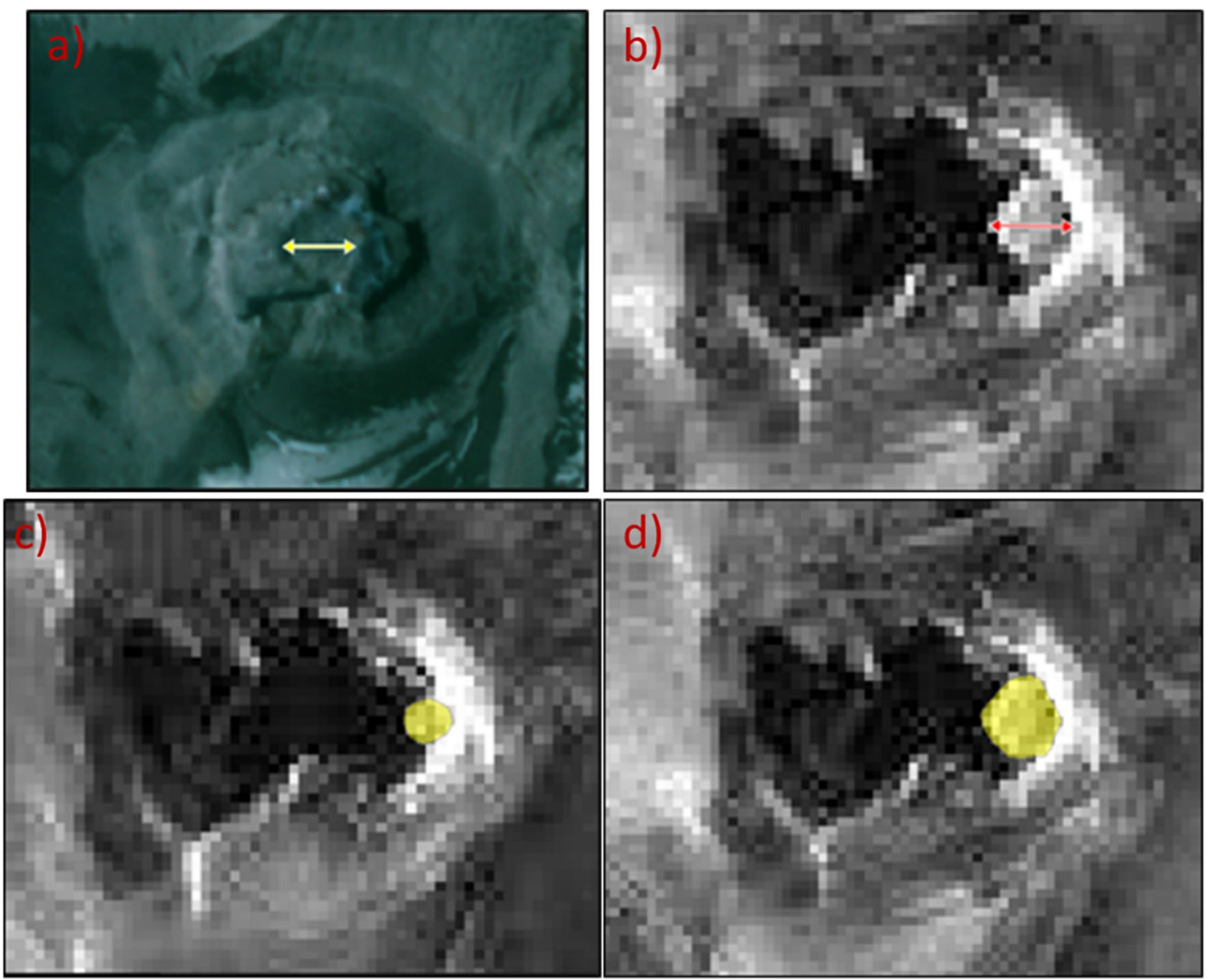

Fig. 10 Example of proposed method to calculate the area and volume over time of the lava dome: a reference for dome dimensions established from Planet Scope image (March 14, 2018). b Scaling from TerraSAR-X image (April 9, 2018). c Example of digitized polygon defining the dome perimeter and area during November 11,2015. d Example of digitized polygon defining the dome perimeter and area during May 25, 2018 


\section{Appendix B. Cross-correlation method used in this work} The data recorded by a sensor $n(n=C o r H)$ is represented by $X_{n}$. We represent the cross-correlation function between $X_{C}$ and $X_{H}$ by $R\left(X_{C}, X_{H} ; \tau\right)$, where $\tau$ is the time delay of $X_{H}$ to $X_{C}$. The cross-correlation coefficient, $\mathrm{CC}\left(X_{C}, X_{H} ; \tau\right)$ is

$$
\mathrm{CC}\left(X_{C}, X_{H} ; \tau\right)=\frac{R\left(X_{C}, X_{H} ; \tau\right)}{\sqrt{P\left(X_{C}\right)} \sqrt{P\left(X_{H}\right)}},
$$

where $P\left(X_{n}\right)=R\left(X_{n}, X_{n} ; 0\right)$, which is the power of $X_{n}$. We assume the data $X_{n}$ consists of pressure fluctuation from infrasound signals, $A_{n}$, seismic-to-infrasonic converted wave, $S_{n}$, wind noise, $W_{n}$, and instrumental noise, $N_{n}$. Namely,

$$
X_{n}=A_{n}+S_{n}+W_{n}+N_{n}
$$

The component $S_{n}$ is usually negligible unless the ground velocity is very large. We have confirmed using some earthquake events that the infrasound stations used in this study recorded pressure oscillation less than $1 \mathrm{~Pa}$ for the vertical ground velocity of around $1 \mathrm{~mm} / \mathrm{s}$, which is in the typical range of the local atmospheric response to the ground motion (Ichihara et al. 2012; Watada et al., 2006). Because the ground velocity of seismic waves related to eruptions at NRV is too small to be recorded by the infrasonic stations, we omit $S_{n}$ in the following discussion.

In principle, there is no correlation between each other of $A_{n}, W_{n}$, and $N_{n}$. It is also confirmed that the correlation of the instrumental noise of the collocated two sensors is negligible. Then, the cross-correlation coefficient between the sensor ' $\mathrm{C}$ ' and ' $\mathrm{H}$ ' is approximated by

$$
\mathrm{CC}\left(X_{C}, X_{H} ; \tau\right)=\frac{R\left(A_{C}, A_{H} ; \tau\right)+R\left(W_{C}, W_{H} ; \tau\right)}{\sqrt{P\left(A_{C}\right)+P\left(W_{C}\right)+P\left(N_{C}\right)} \sqrt{P\left(A_{H}\right)+P\left(W_{H}\right)+P\left(N_{H}\right)}},
$$

Shields (2005) investigated the correlation length of wind noise using a microphone array and showed that the correlation decays with distance, $x$, as

$$
\mathrm{CC}\left(X_{C}, X_{H} ; \tau\right)=\frac{R\left(W_{C}, W_{H} ; \tau\right)}{\sqrt{P\left(W_{C}\right)} \sqrt{P\left(W_{H}\right)}} \sim \exp \left(-\frac{3.2 x f}{v}\right),
$$

where $f$ is the frequency and $v$ is the wind speed. Substituting (B.4) to (B.3) and assuming $P\left(W_{C}\right) \sim P\left(W_{H}\right)$, we obtain

$$
\mathrm{CC}\left(X_{C}, X_{H} ; \tau\right) \sim \frac{R\left(A_{C}, A_{H} ; \tau\right)+\exp \left(-\frac{3.2 x f}{v}\right) P\left(W_{C}\right)}{\sqrt{P\left(A_{C}\right)+P\left(W_{C}\right)+P\left(N_{C}\right)} \sqrt{P\left(A_{H}\right)+P\left(W_{H}\right)+P\left(N_{H}\right)}} .
$$

In order to detect the infrasound signal, the second term of the numerator must be small enough compared with the first term. The second term is reduced if $\frac{3.2 x f}{v}>1$. Considering $x>5$ between the two sensors and assuming $v<20$ for most of the time, we used the frequency range of $f>1.5 \mathrm{~Hz}$.
The time lag $\tau$ which makes $R\left(A_{C}, A_{H} ; \tau\right)$ the largest is expected to be close to zero, because the sensor pairs at the individual stations are close and aligned perpendicular to the direction of the crater (Fig. 1). However, the propagation direction can be locally fluctuate depending on the wind conditions, we evaluate $\operatorname{CC}\left(X_{C}, X_{H} ; \tau\right)$ by the mean value for $-0.02<\tau<0.02 \mathrm{~s}$. Because the $C C$ changes sharply with $\tau$ when the wavelength of the infrasound is not long enough compared with the sensor separation distance, we limit the frequency used in the analyses below $8 \mathrm{~Hz}$, which corresponds to the wavelength of $40 \mathrm{~m}$ for the sound speed of $320 \mathrm{~m} / \mathrm{s}$.

Equation (5) also indicates that when $P\left(W_{C}\right) \gg R\left(A_{C}, A_{H} ; 0\right) \sim P\left(A_{C}\right), \quad C C$ is significantly reduced by the wind noise. In other words, we may detect an infrasonic signal when it arrives in time windows with small $P\left(W_{C}\right)$. Therefore, we define the 'acoustic visibility' by the probability of the time window in which $P\left(W_{C}\right)$ is smaller than a threshold. The threshold depends on the strength of the infrasound signals of interest.

Received: 23 December 2019 Accepted: 18 May 2020

Published online: 05 June 2020

\section{References}

Allstadt K, Malone SD (2014) Swarms of repeating stick-slip icequakes triggered by snow loading at Mount Rainier volcano. J Geophys Res Earth Surf 119:1180-1203. https://doi.org/10.1002/2014JF003086

Cannata A, Montalto P, Patane D (2013) Joint analysis of infrasound and seismic signals by cross wavelet transform: detection of Mt. Etna explosive activity. Nat Hazards Earth Syst Sci 13:1669-1677. https://doi.org/10.5194/ nhess-13-1669-2013

Carmichael JD, Pettit EC, Hoffman M, Fountain A, Hallet B (2012) Seismic multiplet response triggered by melt at Blood Falls, Taylor Glacier, Antarctica. J Geophys Res 117(F03004):1-16. https://doi.org/10.1029/2011JF00222

Castaño-López LM, García-Cano LC, Galvis-Arenas BE, López-Vélez CM, Sanabria O, Acevedo AE (2017) Caracterización de la actividad eruptiva 2010-2017 del volcán Nevado del Ruiz a partir de datos sismológicos. In: Memories of XVI Congreso Colombiano de Geología (eds) (in Spanish), Santa Marta, August 28-September 01, 2017, p 1953. ISBN: 978-958-57950-3-7

Ceballos-Hernández JA, Martínez-Tabares, LM, Valencia-Ramírez LG, PulgarínAlzate BA, Correa-Tamayo AM, Narváez-Marulanda BL (2019) Geological evolution of the Nevado del Ruiz Volcanic Complex. In: Gómez J, PinillaPachon AO (eds) The Geology of Colombia, Volume 4 Quaternary Servicio Geológico Colombiano, Bogotá. Publicaciones Geológicas Especiales 38, pp 283-327. https://doi.org/10.32685/pub.esp.38.2019

Coppola D, Piscopo D, Staudacher T, Cigolini C (2009) Lava discharge rate and effusive pattern at Piton de la Fournaise for MODIS data. J Volcanol Geotherm Res 184(12):174-192. https://doi.org/10.1016/j.jvolgeores .2008.11.031

Coppola D, Laiolo M, Cigolini C, Donne DD, Ripepe M (2016) Enhanced volcanic hot-spot detection using MODIS IR data: results from the MIROVA system. In: Harris AJL, De Groeve T, Garel F, Carn SA (eds). Detecting, Modelling and Responding to Effusive Eruptions. Geol Soc London, Spec Publ 426(1):181-205. https://doi.org/10.1144/sp426.5

Dean KG, Dehn J (eds) (2015) Monitoring volcanoes in the North Pacific: observations from space. Springer-Verlag GmbH Berlin, Heidelberg

Dean K, Servilla M, Roach A, Foster B, Engle K (1998) Satellite monitoring of remote volcanoes improves study efforts in Alaska. EOS Trans Am Geophys Union 79(35):413-423. https://doi.org/10.1029/98EO00316 
Dehn J, Dean KG, Engle K, Izbekov P (2002) Thermal precursors in satellite images of the 1999 eruption of Shishaldin Volcano. Bull Volcanol 64(8):525-534. https://doi.org/10.1007/s00445-002-0227-0

Delgado GH, Julio MP, Carrasco NG, Pulgarín AB, Mothes P, Moreno RH, Cáceres CBE, Cortés RJ (2015) Hazards at Ice-Clad Volcanoes: Phenomena, processes and examples from Mexico, Colombia, Ecuador, and Chile. In: Shroder JF, Haeberli A, Whiteman C (eds) Snow and Ice-related hazards, risks and disasters. Elsevier, Boston

Ekström G, Nettles M, Abers GA (2003) Glacial earthquakes. Science 302(5645):622-624. https://doi.org/10.1126/science.1088057

Evers LG, Haak HW (2005) The detectability of infrasound in the Netherlands from the Italian volcano Mt. Etna. J Atmos Sol Terr Phys 67(3):259-268. https://doi.org/10.1016/j.jastp.2004.09.002

Gaunt HE, Sammonds PR, Meredith PG, Chadderton A (2016) Effect of temperature on the permeability of lava dome rocks from the 2004-2008 eruption of Mount St Helens. Bull Volcanol 78:30. https://doi.org/10.1007/ s00445-016-1024-5

Goerke VH, Young JM, Cook RK (1965) Infrasonic observations of the May 16, 1963, volcanic explosion on the island of Bali. J Geophys Res 70(24):60176022. https://doi.org/10.1029/JZ070i024p06017

Harris AJL, Pilger E, Flynn LP, Garbeil H, Mouginis- Mark PJ, Kauahikaua J, Thornber C (2001) Automated, high temporal resolution, thermal analysis of Kilauea volcano, Hawai'i, using GOES satellite data. Int J Rem Sens 22(6):945-967. https://doi.org/10.1080/014311601300074487

Ichihara M, Takeo M, Yokoo A, Oikawa J, Ohminato T (2012) Monitoring volcanic activity using correlation patterns between infrasound and ground motion. Geophys Res Lett 39(L044304):1-5. https://doi. org/10.1029/2011GL050542

Johnson JB, Aster RC, Ruiz MC, Malone SD, McChesney PJ, Lees JM, Kyle PR (2003) Interpretation and utility of infrasonic records from erupting volcanoes. J Volcanol Geotherm Res 121(1-2):15-63. https://doi.org/10.1016/ S0377-0273(02)00409-2

Kaneko T, Yasuda A, Ishimaru T, Takagi M, Wooster MJ, Kagiyama T (2002) Satellite hot spot monitoring of Japanese volcanoes: a prototype AVHRRbased system. Adv Envirom Mon Mod 1(1):125-133

Kaneko T, Takasaki K, Yasuda A, Aoki Y (2006) Thermal surveillance of the Asama 2004-2005 activity using MODIS nighttime infrared images. Bull Volcanol Soc Japan 51(4):273-282. https://doi.org/10.18940/kazan.51.4_273 (in Japanese with English abstract)

Kaneko T, Yasuda A, Aoki Y, Kajiwara K, Kitagawa S (2010a) Realtime monitoring of active volcanoes in East Asia using MODIS and MTSAT data and its advancement by GCOM-C1 SGLI. Int Arch Photogramm Remote Sens Spat Inf Sci 38(8):209-212

Kaneko T, Den T, Takasaki K, Yasuda A, Maeno F, Koyama E, Nakada S (2010b) MTSAT Observation of the Eruption Cloud Occurred at the February 2, 2009 Eruption of Mt Asama, Central Japan. J Volcanol Soc Japan 55(2):119-128. https://doi.org/10.18940/kazan.55.2_119 (in Japanese with English abstract)

Kaneko T, Maeno F, Yasuda A, Takeo M, Takasaki K (2019) The 2017 Nishinoshima eruption: combined analysis using Himawari-8 and multiple high-resolution satellite images. Earth Planets Space. 71(140):1-18. https ://doi.org/10.1186/s40623-019-1121-8

Lacanna G, Ichihara M, Iwakuni M, Takeo M, Iguchi M, Ripepe M (2014) Influence of atmospheric structure and topography on infrasonic wave propagation. J Geophys Res 119(4):2988-3005. https://doi.org/10.1002/2013J B010827

Laiolo M, Ripepe M, Cigolini C, Coppola D, Della Schiava M, Genco R, Innocenti L, Lacanna G, Marchetti E, Massimetti F, Silengo MC (2019) Space- and ground-based geophysical data tracking of magma migration in shallow feeding system of mount Etna volcano. Remote Sens. 11:10. https://doi. org/10.3390/rs11101182

Le Pichon A, Vergoz J, Cansi Y, Ceranna L, Drob D (2010) Contribution of infrasound monitoring for atmospheric remote sensing. In: Le Pichon A, Blanc E, Hauchecorne A (eds) Infrasound monitoring for atmospheric studies. Springer, Heidelberg, p 734

Lombardi D, Gorodetskaya I, Barruol G, Camelbeeck T (2019) Thermally induced icequakes detected on blue ice areas of the East Antarctic sheet. Ann Glaciol 60(79):45-56. https://doi.org/10.1017/aog.2019.26

Londono JM (2016) Evidence of recent deep magmatic activity at Cerro BravoCerro Machín volcanic complex, central Colombia. Implications for future volcanic activity at Nevado del Ruiz, Cerro Machín and others volcanoes.
J Volcanol Geotherm Res 324:156-168. https://doi.org/10.1016/j.jvolg eores.2016.06.003

Londono JM, Galvis BE (2018) Seismic data, photographic images and physical modeling of volcanic plumes as a tool for monitoring the activity of Nevado del Ruiz Volcano, Colombia. Front Earth Sci 6(162):1-20. https:// doi.org/10.3389/feart.2018.00162

Lopez T, Fee D, Prata F, Dehn J (2013) Characterization and interpretation of volcanic activity at Karymsky Volcano, Kamchatka, Russia, using observations of infrasound, volcanic emissions, and thermal imagery. Geochem Geophy Geosyst 14(12):5106-5127. https://doi.org/10.1002/2013GC0048 17

Lundgren P, Samsonov SV, López Velez CM, Ordoñez M (2015) Deep source model for Nevado del Ruiz Volcano, Colombia, constrained by interferometric synthetic aperture radar observations. Geophys Res Lett 42(12):4816-4823. https://doi.org/10.1002/2015GL063858

Marchetti E, Ripepe M, Gampus P, Le Pichon A, Vergoz J, Lacanna G, Mialle $P$, Héreil $P$, Husson $P$ (2019) Long range infrasound monitoring of Etna volcano. Sci Rep. https://doi.org/10.1038/s41598-019-54468-5

Martínez LM, Zuluaga I, Ceballos JA (2012) Informe Sobre la Actividad Eruptiva del Volcán Nevado del Ruiz: Mayo 29 y Junio 30 de 2012. SGC_Observatory volcanologic and seismologic of Manizales informe interno 67 (In Spanish)

Martínez LM, Valencia LG, Ceballos JA, Narváez BL, Pulgarín BA, Correa AM, Navarro SdelR, Murcia HF, Zuluaga I, Rueda JB, Pardo N (2014) Geología y estratigrafía del complejo volcánico Nevado del Ruiz. SGC - Observatory volcanologic and seismologic of Manizales informe interno (In Spanish)

Matoza RS, Hedlin MAH, Garces MA (2007) An infrasound array study of Mount St Helens. J Volcanol Geoth Res 160(3-4):249-262. https://doi. org/10.1016/j.jvolgeores.2006.10.006

Matoza RS, Green DN, Le Pichon A, Shearer PM, Fee D, Mialle P, Ceranna L (2017) Automated detection and cataloging of global explosive volcanism using the International Monitoring System infrasound network. J Geophys Res 122(4):2946-2971. https://doi.org/10.1002/2016JB013356

McKee K, Fee D, Haney M, Matoza RS, Lyons J (2018) Infrasound signal detection and back azimuth estimation using ground-coupled airwaves on a seismo-acoustic sensor pair. J Geophys Res-Sol EA 123(8):6826-6844. https://doi.org/10.1029/2017JB015132

Métaxian J-P (2003) Seismicity related to the glacier of Cotopaxi Volcano, Ecuador. Geophys Res Lett 30(9):1483. https://doi.org/10.1029/2002GL016773

Neave KG, Savage JC (1970) Icequakes on the Athabasca Glacier. J Geophys Res 75(8):1351-1362. https://doi.org/10.1029/JB075i008p01351

Oppenheimer C (1998) Volcanological applications of meteorological satellites. Int J Remote Sens 19(15):2829-2864

Pallister JS, Cashman KV, Hagstrum JT, Beeler NM, Moran SC, Denlinger RP (2013) Faulting within the Mount St. Helens conduit and implications for volcanic earthquakes. Geol Soc Am Bull 125(3-4):359-376. https://doi. org/10.1130/b30716.1

Passechnik IP (1959) Seismic and air waves which arose during an eruption of the volcano Bezymianny on March 30, 1956. In: Izv AN SSSR Ser Geophysics 9:1121-1126 (Engl. Transl.)

Podolskiy EA, Walter F (2016) Cryoseismology. Rev Geophys 54(4):708-758. https://doi.org/10.1002/2016RG000526

Podolskiy EA, Fujita K, Sunako S, Tsushima A, Kayastha RB (2018) Nocturnal thermal fracturing of a Himalayan debris covered glacier revealed by ambient seismic noise. Geophys Res Lett 45(18):9699-9709. https://doi. org/10.1029/2018GL079653

Preiswerk LE, Walter F, Anandakrishnan S, Barfucci G, Beutel J, Burkett P, Dalban Canassy P, Funk M, Limpach P, Marchetti E, Meier L, Neyer F (2016) Monitoring unstable parts in the ice-covered Weissmies northwest face. In: ETH Zurich Res Coll Proceedings of the 13th Interpraevent Congress, Lucerne, 434-443. https://doi.org/10.3929/ethza-010811690

Reaht KA, Ramsey MS, Dehn J, Webley PW (2016) Predicting eruptions from precursory activity using remote sensing data hybridization. J Volcanol Geoth Res 321:18-30. https://doi.org/10.1016/j.jvolgeores.2016.04.027

Ripepe M, Marchetti E (2002) Array tracking of infrasonic sources at Stromboli volcano. Geophys Res Lett 29(22):33-34. https://doi.org/10.1029/2002g 1015452

Ripepe M, Marchetti E, Ulivieri G (2007) Infrasonic monitoring at Stromboli Volcano during the 2003 effusive eruption: insights on the explosive and degassing process of an open conduit system. J Geophys Res-Sol EA 112(B09207):1-13. https://doi.org/10.1029/2006JB004613 
Ripepe M, Marchetti E, Delle Donne D, Genco R, Innocenti L, Lacanna G, Valade S (2018) Infrasonic early warning system for explosive eruptions. J Geophys Res 123(11):9570-9585. https://doi.org/10.1029/2018JB015561

Rothery DA, Francis PW, Wood CA (1988) Volcano monitoring using short wavelength infrared data from satellites. Jour Geophys Res 93:7993-8008

SGC Servicio Geológico Colombiano (2015) Informe anual de actividad de los volcanes del Segmento Norte de Colombia Enero-Diciembre 2015. Internal Report in Spanish. https://www.sgc.gov.co/Publicaciones/Infor mes\%20tcnicos/Informe\%20t\%C3\%A9cnico\%20anual\%20de\%20201 5.pdf

SGC Servicio Geológico Colombiano (2016) Informe anual de actividad de los volcanes del Segmento Norte de Colombia Enero-Diciembre 2016. Internal Report in Spanish. https://www.sgc.gov.co/Publicaciones/Infor mes\%20tcnicos/Informe\%20T\%C3\%A9cnico\%20Anual\%202016.pdf

SGC Servicio Geológico Colombiano (2017) Informes mensuales de actividad de los volcanes del Segmento Norte de Colombia Enero to December 2017. Internal Reports in Spanish. https://www2.sgc.gov.co/Publicacio nes/Paginas/informes-tecnicos.aspx

SGC Servicio Geológico Colombiano (2018) Informes mensuales de actividad de los volcanes del Segmento Norte de Colombia Enero to December 2018. Internal Reports in Spanish. https://www2.sgc.gov.co/Publicacio nes/Paginas/informes-tecnicos.aspx

Shields FD (2005) Low-frequency wind noise correlation in microphone arrays. J Acoust Soc Am 117:3489. https://doi.org/10.1121/1.1879252

Smith R, Sammonds PR, Tuffen H, Meredith PG (2011) Evolution of the mechanics of the 2004-2008 Mt. St Helens lava dome with time and temperature. Earth Planet Sci Lett 307(1):191-200. https://doi.org/10.1016/j. epsl.2011.04.044

St. Lawrence WS, Qamar A (1979) Hydraulic transients: a seismic source in volcanoes and glaciers. Science 203(4381):654-656. https://doi.org/10.1126/ science.203.4381.654
Thelen WA, Cooper J (2014) An analysis of three new infrasound arrays around Kilauea Volcano. U.S. Geological Survey Open-File Report 2014-1253. https://dx.doi.org/10.3133/ofr20141253

Ulivieri G, Ripepe M, Marchetti E (2013) Infrasound reveals transition to oscillatory discharge regime during lava fountaining: implication for early warning. Geophys Res Lett 40(12):3008-3013. https://doi.org/10.1002/ grl.50592

Watada S, Kunugi T, Hirata K, Sugioka H, Nishida K, Sekiguchi S, Oikawa J, Tsuj Y, Kanamori $\mathrm{H}$ (2006) Atmospheric pressure change associated with the 2003 Tokachi-Oki earthquake Geophys. Res Lett 33:L24306. https://doi. org/10.1029/2006GL027967

Wooster MJ, Rothery DA (1997) Thermal monitoring of Lascar volcano, Chile, using infrared data from the Along-Track Scanning Radiometer: a 1992-1995 time series. Bull Volcanol 58:566-579

Wright R, Flynn L, Garbeil H, Harris A, Pilger E (2002) Automated volcanic eruption detection using MODIS. Remote Sens Environ 82(1):135-155. https:// doi.org/10.1016/S0034-4257(02)00030-5

Wright R, Flynn LP, Garbeil H, Harris AJL, Pilger E (2004) MODVOLC: near-realtime thermal monitoring of global volcanism. J Volcanol Geotherm Res 135(1-2):29-49. https://doi.org/10.1016/j.jvolgeores.2003.12.008

Zhang T, Chen Y, Ding M, Zhongyan S, Yang Y, Guan Q (2019) Air-temperature control on diurnal variations in microseismicity at Laohugou Glacier No 12, Qilian Mountains. Ann Glaciol 60(79):125-136. https://doi. org/10.1017/aog.2018.34

\section{Publisher's Note}

Springer Nature remains neutral with regard to jurisdictional claims in published maps and institutional affiliations.

\section{Submit your manuscript to a SpringerOpen ${ }^{\circ}$ journal and benefit from:}

- Convenient online submission

- Rigorous peer review

- Open access: articles freely available online

- High visibility within the field

- Retaining the copyright to your article

Submit your next manuscript at springeropen.com 